\title{
COMPOSITE PRESSURE VESSELS
}

\author{
RAO YARRAPRAGADA K.S.S ${ }^{1}$, R.KRISHNA MOHAN ${ }^{2}$, B.VIJAY KIRAN ${ }^{3}$ \\ ${ }^{1,2,3}$ Associate Professor, Mechanical Department, B.V.C College of Engineering, Andhra Pradesh, India, \\ subbaroayarrapragada@gmail.com,smilesmile.mohan@gmail.com,b.vijaykiran@gmail.com
}

\begin{abstract}
Cylindrical pressure vessels are widely used for commercial, under water vehicles and in aerospace applications. At present the outer shells of the pressure vessels are made up of conventional metals like steels and aluminum alloys. The payload performance/ speed/ operating range depends upon the weight. The lower the weight the better the performance, one way of reducing the weight is by reducing the weight of the shell structure. The use of composite materials improves the performance of the vessel and offers a significant amount of material savings. Moreover, the stacking sequence is very crucial to the strength of the composite material. This Project involves various objective functions such as stiffness, buckling load and Weight at each level of optimization. Usually composite pressure vessels are designed for minimum mass under strength constraints. A graphical analysis is presented to find optimum fiber orientation for given layer thicknesses. In the present work, an analytical model is developed for the Prediction of the minimum buckling load with / without stiffener composite shell of continuous angle ply laminas $\left( \pm 45^{\circ}, \pm 55^{\circ}, \pm 65^{\circ}, \pm 75^{\circ}, \pm 85^{\circ}\right)$ for investigation. Comparisons are made for two different approaches i.e. the finite element model and the theoretical model. A 3 -D finite element analysis is built using ANSYS-12.0 version software into consideration, for static and buckling analysis on the pressure vessel.
\end{abstract}

Index Terms: Composite material, Shells, Fiber orientation, Layer thickness, Stiffeners, Critical Pressure and Buckling $* * * * * * *$

\section{INTRODUCTION}

Pressure vessels are important because many liquids and gases must be stored under high pressure. Special emphasis is placed upon the strength of the vessel to prevent explosions as a result of rupture. Codes for the safety of such vessels have been developed that specify the design of the container for specified conditions. Most pressure vessels are required to carry only low pressures and thus are constructed of tubes and sheets rolled to form cylinders. Some pressure vessels must carry high pressures, however, and the thickness of the vessel walls must increase in order to provide adequate strength. Interest in studying of the shell arises from the fifties of twentieth century. The assemblies, containing thin shells, find wide use in the modern engineering, especially in ships, aircraft and spacecraft industry. The shell vibrations and buckling modes are analyzed by means of numerical methods, to clarify qualitatively the critical loads and different buckling modes.

In today's aerospace and aircraft industries, structural efficiency is the main concern. Due to their high specific strength and light weight, fiber reinforced composites find a wide range of applications. Light weight compression load carrying structures form part of all aircraft, and space vehicle fuel tanks, air cylinders are some of the many applications. In the present work, design analysis of fiber reinforced multi layered composite shell, with optimum fiber orientations; minimum mass under strength constraints for a cylinder with or without stiffeners under axial loading for static and buckling analysis on the pressure vessel has been studied. Cylindrical shells (see Fig.1.1) such as thin-walled laminated composite unstiffened vessels like deep submarine exploration housings and autonomous underwater vehicles are subjected to any combination of in plane, Out of plane and shear loads due to the high external hydrostatic pressure during their application. Due to the geometry of these structures, buckling is one of the most important failure criteria. Buckling failure mode of a stiffened cylindrical shell can further be subdivided into global buckling, local skin buckling and stiffener crippling. Global buckling is collapse of the whole structure, i.e. collapse of the stiffeners and the shell as one unit. Local skin buckling and the stiffeners crippling on the other hand are localized failure modes involving local failure of only the skin in the first case and the stiffeners in the second case.

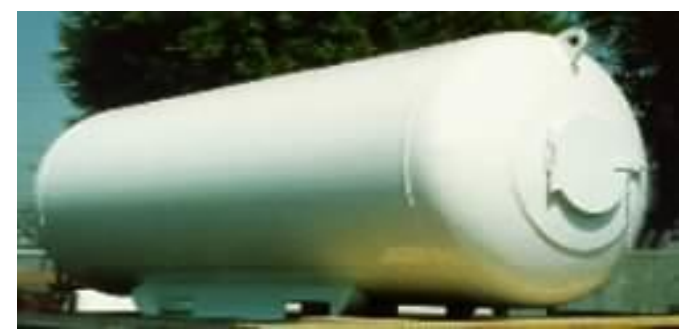

Fig 1.1.Cylindrical Pressure Vessel

In the present work, an analytical model is developed for prediction of optimum fiber orientations for given layer thicknesses, and mainly minimum buckling load for with or 
without stiffener composite shell under multilayered continuous angle-ply loading condition is investigated. The model developed is more general in the sense that any configuration of stiffeners, on either one side or both sides of the shell can be modeled accurately. Stiffened shells having either symmetrical or unsymmetrical shell laminates can also be modeled with equal ease using this model.

Grid stiffened cylindrical shells are the shells having a certain kind of stiffening structures either on inner, outer or both sides of the shell and significantly increases the load resistance without much increase in weight. To further reduce the weight, both the shell and the stiffeners are made using fiber reinforced polymers. The promising future of stiffened composite cylinder has in turn led to an extensive research work in this area.

For the sake of analysis, shell elements (shell $91 \&$ solid 46) were used and analysis was carried out with the aid of the commercial package, ANSYS-12.0. Due to the expensive nature of composite cylinder test specimens, experimentation could not be performed.

\subsection{Introduction to Thin Composite Shells}

The shell whose wall thickness is small compared to the radius of curvature and the corresponding radius of twist is known as thin shell. Plate and shell structures are used in a lightweight load bearing structural parts for various modern aerospace, offshore, nuclear, automotive, and civil engineering structures. These shells are subjected to compressive loads. In the case of air crafts, they are subjected to fluctuating flight loads, which also produce compressive components. These compressive loads cause buckling of the shell structure. The analysis of composite shell structures requires consideration of a variety of failure modes. Often analysis programs cannot predict all failure modes using a single analysis model, and consequently structural designers must use a variety of analysis tools. It is also common that for a given failure mode, it is difficult to obtain the same result using different programs. There is no need to argue that composite shells are important in modern technology.

\subsection{Composite Materials}

Composites are considered to be combinations of materials differing in composition or form on a macro scale. The constituents retain their identities in the composite i.e. they do not dissolve or otherwise merge completely into each other although they act in the idea of a composite material is not a new or recent one concert. In nature, one can find out many composite materials, for example wood is a fibrous natural composite (cellulose fibrous in lignin matrix). Bone is yet another example of natural composites. Our ancestors invented composite by mixing straw and clay to make bricks. Straw is fiber reinforcement and clay is the matrix. The first glass fiber reinforced polymer was developed in 1940. The origin of distinct discipline of composite materials started in 1960's.Extensive research has been done on composite material since 1965. One difference between laminated composites and traditional engineering materials is that a composite's response to loads is direction dependent. Monolithic metals and their alloys can't always meet the demands of today's advanced technologies. The composite materials exhibit high specific strength and high specific modulus resulting in substantial reduction of weight of the components, thus improves efficiency, and results in energy savings. One of the main advantages of composite materials is the flexibility involved in getting the desired strength and stiffness in the direction required. Carbon fibers are very common in high-modulus and high-strength applications.

It is well known that the measured strength of most materials is much smaller than their theoretical strength because of presence of imperfections or inherent flaws in the materials. Flaws in the form of cracks that lies perpendicular to the direction of load are particularly detrimental to the strength. It is found that non polymeric materials have higher strength along their lengths because of small cross sectional fibers, the flaws are minimized.

In case of polymeric materials, orientation of the molecular structure is responsible for high strength and stiffness. Fibers because of their small-sectional dimensions are not directly usable in engineering applications. They are embedded in matrix materials to form fibrous composites. The matrix serves to bind the fibers together; transfer loads to the fibers and protects them against environmental attack and damage due to handling. The shell is multi-layered fibrous composite shell. Each layer or lamina is a single-layer composite and thus orientation is varied according to design. Each layer is vary thin (thickness $0.4 \mathrm{~mm}$ to $0.7 \mathrm{~mm}$ ) and cannot be directly used. Several identical or different layers are bonded together to form a multi-layered composite shell. Each layer may be differing from another layer in (a) Relative volumes of the constituent's materials (b) Form of the reinforcement. (c) Orientation of fibers with respect to common reference axes. Thus the directional properties of the individual layers may be quite different from each other. 


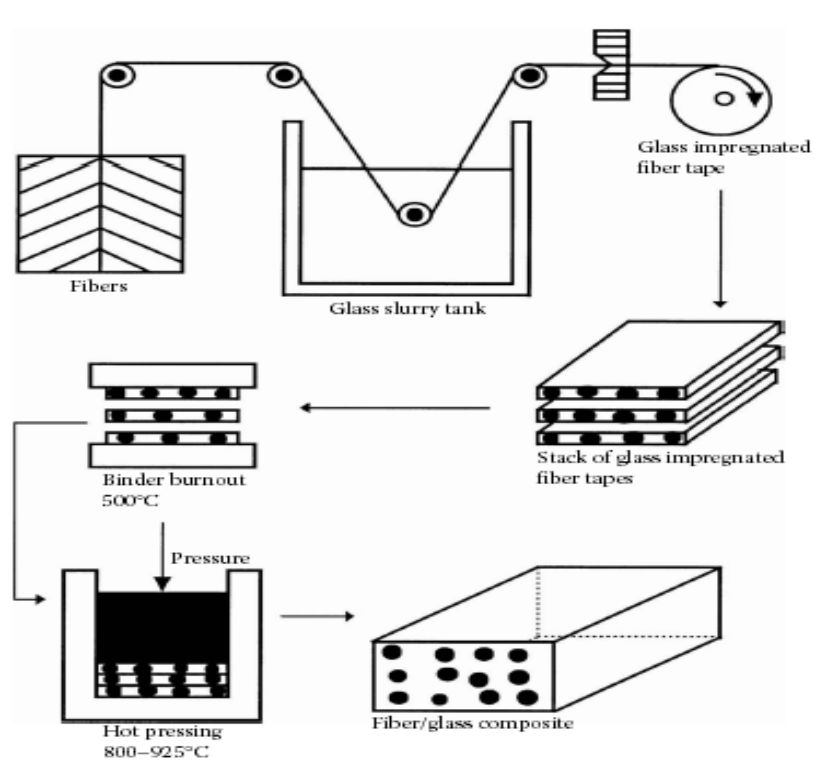

Fig. 1.2. Schematic Matrix Composite Laminates Manufacturing

One of the most common methods to manufacture matrix composites is called the hot pressing method. Glass fibers in continuous tow are passed through slurry consisting of powdered matrix material, Solvent such as alcohol, and an organic binder as shown in fig 1.2. The tow is then wound on a drum and dried to form Prepreg tapes. The prepreg tapes can now be stacked to make a required laminate; heating at about $932^{\circ} \mathrm{F}\left(500^{\circ} \mathrm{C}\right)$ burns out the binder. Hot pressing at high temperatures of about $1832^{\circ} \mathrm{F}\left(1000^{\circ} \mathrm{C}\right)$ and pressures of 7 to $14 \mathrm{Mpa}$. Design analysis of any composite structural element would require a complete knowledge of properties of individual layers. Each layer is a continuous angle-ply composite laminate consists of parallel fibers embedded in a matrix. Several unidirectional layers can be stacked in a specified sequence of orientation to fabricate a laminate that will meet design strength and stiffness requirements. Each layer of a unidirectional composite may be referred to as simple a layer ply or lamina. One of the most important factors for determining the properties of composites is relative proportions of the matrix and reinforced materials. The relative proportionate can be given as the weight fractions or by one of the experimental methods after fabrication. The volume fractions are exclusively used in the theoretical analysis of composite materials. Most manmade composite materials made from two materials, these are a reinforced material called fiber and a base material called matrix. For example in concrete columns the concrete is base material which is called matrix and the iron rods come under fibers for reinforcement.Their existing three types of composites.

1. Fibrous Composites: It consists of fibers of one material in a matrix material of another material.
2. Particulate Composites: These are composed of particles of one material in a matrix of another material.

3. Laminate Composites: These are made of layers in which fibers and matrix are made of different materials, including the composites.

The purpose of matrix is to transfer loads and protect them against environmental attack and damage due to handling. Based upon the properties required, the matrix and fiber materials are selected.

\subsubsection{Fiber}

Fibers are principal constituents in fiber reinforced composite material. They occupy the large volume fraction in a composite laminate and share major portion of load acting on a composite.

- Glass is the most common fiber used in polymer matrix composites. Its advantage including its high strength, low cost, high chemical resistance and good insulating properties.

- Carbon fibers are very common in high-modulus and high-strength applications. The advantages of carbon fibers include high specific strength and modulus, low coefficient of thermal expansion and high fatigue strength.

- Aramid fiber is an aromatic organic compound made of carbon, hydrogen, oxygen and nitrogen. Its advantages are low density, high tensile strength, low cost and high impact resistance.

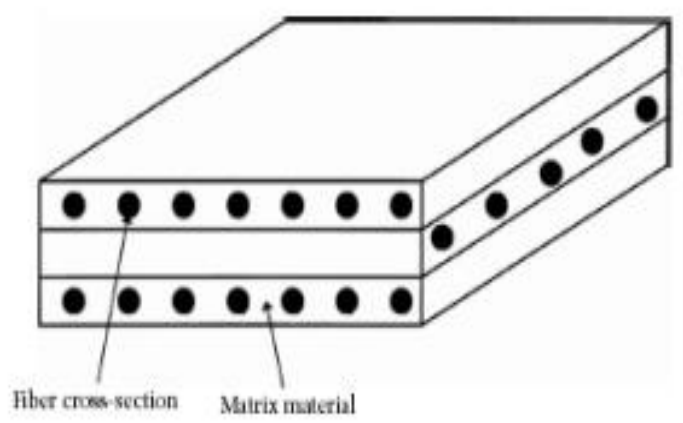

Fig1.3.Typical Laminate made of three laminate

\subsubsection{Matrix}

Use of fibers by themselves as matrix is limited, because of smaller dimensions. Therefore fibers are used as reinforcement to matrices.

The role of matrix in a fiber - reinforced composite material is

(1) To transfer stresses between the fiber.

(2) To provide a barrier against an adverse environment. 
(3) To protect the surface of the fiber from mechanical abrasion.

The matrix plays a minor role in load carrying capacity. The matrix has a major influence on Inter laminar shear as well as in plane shear properties of the composite. Inter laminar shear strength is important in design under bending loads. In plane shear, strength is important in design under tensional loads. The matrix provides lateral support against the possibility of fiber buckling under compressive loads. Among the matrix materials epoxies are used because of commercial availability and ease of processing. More than two-thirds of the polymer matrices used in aerospace applications are epoxy based. The main reason why epoxy is the most used polymer matrix material is due to its Advantages over the other matrix:

(1) Wide variety of properties available.

(2) Absence of volatile maters during cure.

(3) Low shrinkage during cure.

(4) Excellent resistance to chemical and solvents.

(5) Excellent adhesion to fibers.

(6) The disadvantages are relatively high cost and long curing time.

\subsubsection{Characteristics of Composites}

Fiber reinforced composite materials offer a combination of strength and elasticity that are better than conventional metallic materials. Composites are superior because of their low specific gravities, high strength-weight ratios and high modulus-weight ratio's. Structural materials such as steel and aluminum alloys are considered isotropic since they exhibit nearly equal properties irrespective of the direction of measurement. In case of composites, properties depend strongly on the direction of measurement. Many fiber reinforced composites have high internal damping which leads to better vibration energy absorption within the material and results in reduced transmission of noise and vibrations to neighboring structures. There are several distinct characteristics that make composites different from many conventional materials.

\subsubsection{Applications of Composite Materials}

The aircraft industry uses composites to meet performance requirements beyond the capabilities of metals. The Boeing 757 , for example, uses approximately $760 \mathrm{ft}^{3}$ of composites in the body and wing components, with an additional $361 \mathrm{ft}^{3}$ used in rubber, elevator, edge panels and tip fairings. The B-2 bomber contains carbon and glass fibers, epoxy resin matrices, and high temperature polyimide as well as other material in more than 10,000 composite components. Composites are also used in race cars, tennis rackets, golf clubs, and other sports and leisure products. Few more applications are given as below
- Space applications

- Automotive applications

- Sporting goods applications

- Marine applications Medical applications

- Commercial goods

\subsection{Lamina and Laminate Analysis}

A lamina (considered a unidirectional composite) is characterized by having all fibers (either a single ply or multiple plies) oriented in the same direction. This model allows one to treat lamina as an orthotropic material. A lamina is a collection of laminates arranged in a specified manner as shown in fig.1.3. Adjacent lamina may be of the same or different materials and their orientations with respect to a reference axis may be arbitrary.

- Single -layered laminates: A single layered laminate is a unidirectional lamina with multiple layers.

- Symmetric Laminates: A symmetric laminates has both geometric and material symmetry with respect to the mid-surface. Geometric symmetry results from having identical lamina orientations above and below the mid surface. Material symmetry can result from either having all lamina the same material, or requiring different lamina to be symmetrically disposed about the mid-surface.

- Antisymmetric Laminates: This laminate is characterized by having its layers arranged in an ant symmetric fashion with respect to the mid surface. There must be even number of plies for a laminate to be ant symmetric.

Cross-ply Laminates: A cross-ply laminate contains an arbitrary number of plies, each with a fiber orientation of either $0^{\circ}$ or $90^{\circ}$, and can be either symmetric or anti symmetric.

Angle-Ply Laminates: Angle-ply laminates have an arbitrary number of layers (n). Each ply has the same thickness and is the same material. The plies halt can be either symmetric or antisymmetric (see fig1.4)

- Aircraft and military applications 


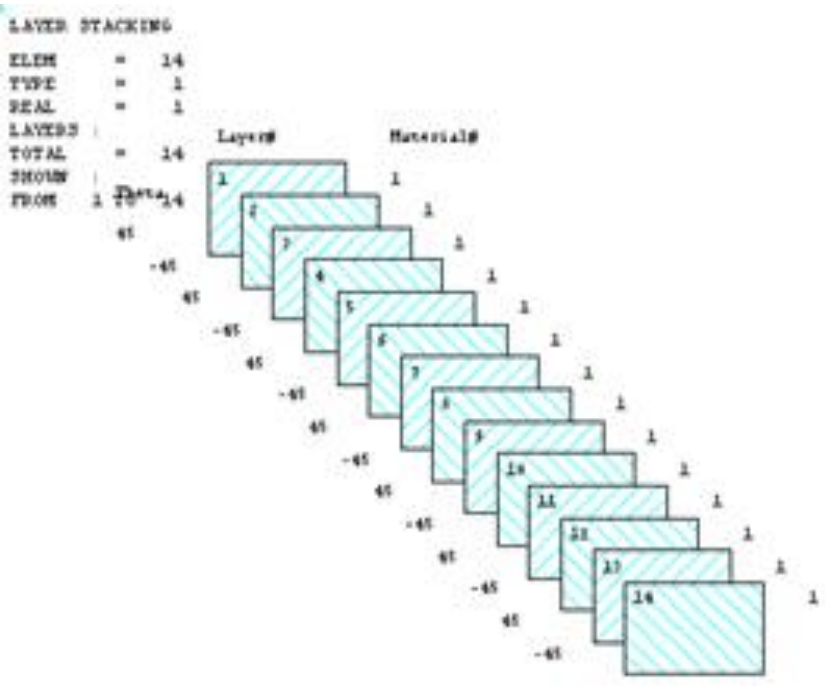

Fig.1.4.Layer stacking

In Filament winding as shown in fig1.5, fibers are impregnated with a resin by drawing them through an in-line resin bath, Depending on the desired properties of the product; winding patterns such as hoop, helical can be developed. The product is then cured with or without heat $\&$ pressure. Each ply is pressed to remove any entrapped air \& wrinkles; the layup is sealed at the edges to form a vacuum seal.
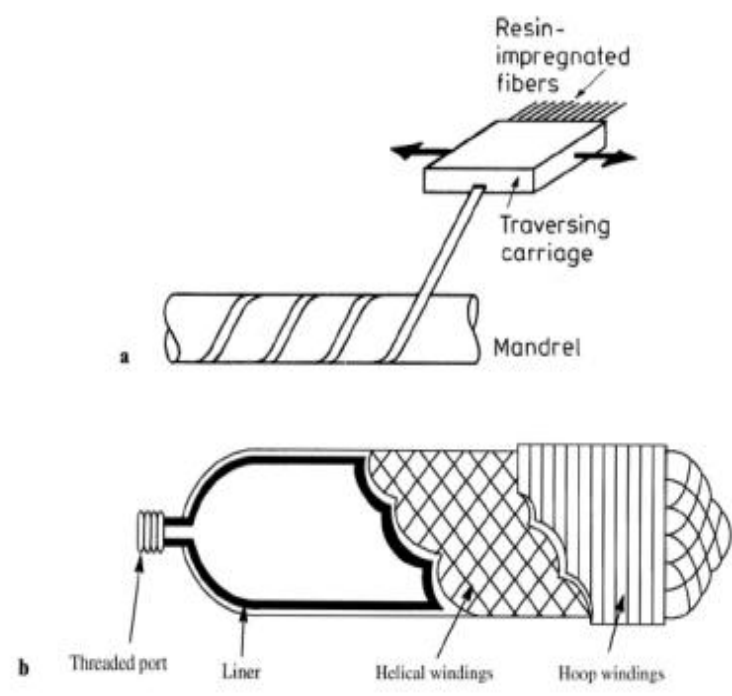

Fig 1.5.Filament wound Pressure Vessel

\subsection{BUCKLING ANALYSIS}

Buckling may be defined as the failure of structure under axial compressive load. The load at which the shell structure becomes unstable under Compressive loads and buckles is known as buckling load. A structure may fail to support its load when a connecting snaps, or it bends until it is useless, or a member in tension either pulls a part or a cracks forms that divides it, or a member in compression crushes and crumbles, or finally, if a member in compression buckles, that is moves laterally and shortens under a load it can no longer support. Of all of these modes of failure, buckling is probably the most and most catastrophic. The ratio of critical stress to the working stress is known as buckling factor. There are three basic types of buckling of thin shells corresponding to the three types of membrane stresses, axial and circumferential normal stress and shear stresses on axial and circumferential surfaces. To cause buckling the axial and circumferential stresses must be compressive. When a structure (usually subjected to compression) undergoes visible large displacements transverse to the load then it is said to buckle. Buckling may be demonstrated by pressing the opposite's edges of a flat sheet of cardboard towards one another. For small loads the process is elastic since buckling displacement disappears when the load is removed. Local buckling of plates or shells is indicated by the growth of bulges, waves or ripples, and is commonly encountered in the component plates of thin structural members. Buckling proceeds in manner which may be either: Stable - In which case displacement increases in a controlled fashion as loads are increased, i.e. the structure's ability to sustain loads is maintained. Unstable In which deformations increase instantaneously, the load carrying capacity nose- dives and the structure collapses catastrophically. Neutral equilibrium is also a theoretical possibility during buckling - this is characterized by deformation increase without change in load. Buckling and bending are similar in that they both involve bending moments. In bending these moments are substantially independent of the resulting deflections, whereas in buckling the moments and deflections are mutually inter-dependent - so moments, deflections and stresses are not proportional to loads. If buckling deflections become too large then the structure fails this is a geometric consideration, completely divorced from any material strength consideration. If a component or part thereof is prone to buckling then its design must satisfy both strength and buckling safety constraints. The behavior of a compressed shell after buckling is quite different to that of a plate; in this case an unstable (negative) stiffness is accompanied by a sudden reduction of load capacity as shown in the fig 1.6.
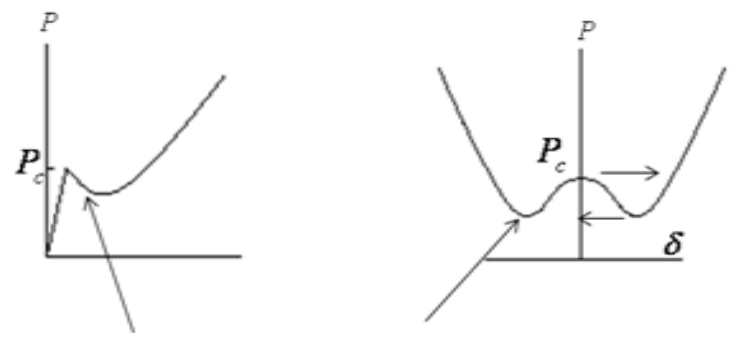

Unstable post-buckling path (snap)

Fig.1.6.Buckling curve 
Since the displacement are uncontrolled in most practical systems, shells behave in a snap-buckling mode i.e. as an increasing load reaches the bifurcation point, the cylinder must undergo an instantaneous increase in deflection ("snap") to the point in order to accommodate the increasing load. A subsequent decrease in load is accommodated by a corresponding decrease in buckling deflection until the point is reached where upon the structure again snaps instantaneously - this time back to the point on the primary path as shown in figure. Clearly this behavior makes it imperative in design to apply large safety factors to the theoretical buckling loads of compressed cylinders.

\section{MATHEMATICAL MODELING}

The mathematical modeling of composite shells involves the theory of lamina and laminate analysis. Laminate is a collection of lamina arranged in specified manner. In order to analyze the response of a laminated composite, it is necessary to predict the behavior of individual lamina. Buckling load calculations of shells without stiffeners involve the load-strain and moment-curvature relations through the laminate analysis and that of the shells with stiffeners require the force and moment interaction relations of the stiffeners and the shell, in order to determine the stiffness contribution of the stiffeners to the total structure. The object of buckling analysis is to estimate the maximum pressure that the composite shell can withstand before it becomes elastically unstable "Windenburg and Trilling Equation" is used to determine composite shell critical buckling pressure. The design philosophy of a composite shell is to avoid failure during a predetermined service life. Failure of a shell depends principally on the type of application involved. Composite laminates containing fiber reinforced thermosetting polymers do not exhibit gross yielding, yet they are also not classic brittle materials. Under a static tensile load, many laminates show non-linear characteristics attributes to sequential ply failures. The current design practice in aerospace industry, marine industries use the first ply failure approach. The crack appearing in the failed ply may make the neighboring plies susceptible to mechanical and environmental damage.

The design criteria for fiber reinforced composite shell uses the same design criteria as those for metals. They are as follows:

1) Must sustain the ultimate design load in static testing.

2) Fatigue life must be equal or exceed the projected vehicle life.

3) Deformations resulting from the applications of repeated loads and limits design load must not interfere with mechanical operation of the system.

\subsection{General Design Guide Lines}

The principal steps in designing a composite laminates are

1) Selection of fiber, resign and fiber volume fraction.

2) Selection of optimum fiber orientation in each ply and the lamina stacking sequence.
3) Selection of number of plies needed in each orientation which also determines the final thickness of the component.

In general symmetric laminates are commonly preferred over unsymmetrical laminates. This eliminates the extension bending coupling represented by the B-matrix. The presence of extension - bending coupling is also undesirable from the stiffness stand point. Since it reduces the effective stiffness of the laminate and thereby increases its deflection, reduces the critical buckling loads and decreases the natural frequency of vibration. Similar but lesser effects are observed if the laminate has bending - twisting coupling due to presence of D16 and D26 terms. If the angle of ply laminates are used the layers with $+\theta$ and $-\theta$ orientations should be altered instead of in clustered configuration. Thus for example an fourteen layer laminate with 7 of $+\theta$ orientations and 7 of $-\theta$ orientations should be designed as $[+\theta /-\theta /+\theta /-\theta]$ s instead of $[+\theta /+\theta /$ $-\theta /-\theta] \mathrm{s}$ or $[+\theta /+\theta /-\theta /-\theta] \mathrm{s}$.

\subsubsection{Angle-ply Laminates}

A Laminate is called an angle ply laminate if it has plies of the same material and thickness and only oriented at $+\theta$ and $\theta$ directions. An example of an angle ply laminate is [45/45/45/-45]

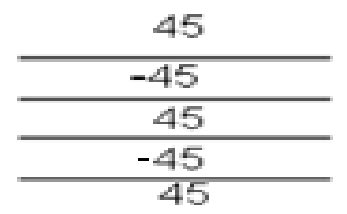

If a laminate has an even number of plies, then $\mathrm{A} 16=\mathrm{A} 26=$ 0 . However, if the number of plies is odd and it consists of alternating $+\theta$ and $-\theta$ plies, Then it is symmetric, giving $[\mathrm{B}]=0$, and A16, A26,D16 and also become small as the number of layers increases for the same laminate thickness. This behavior is similar to the symmetric cross-ply laminates. However, these angle ply laminates have higher shear stiffness and shear Strength properties than cross-ply laminates.

\subsection{Laminated Design Strength}

Ply-by-ply approach for designing symmetric laminates under in-plane and bending loads. An initial laminate configuration is assumed and additional plies are added in a step wise fashion to achieve the most efficient laminate and the margin of safety (ratio of lamina strength to effective lamina stress) for each lamina is calculated. A margin of safety greater than unity indicates a safe ply in the laminate. The process is repeated until the margin of safety in each lamina is greater than unity. Simple optimization procedure to determine the fiber orientation angle $\theta$ for maximum first ply failure stress in symmetric laminates. Such as $[-\theta / 0 /+\theta]$ and so on. The objective function $\mathrm{F}$ was expressed as for a given laminate configuration. The mid plane strain component are the 
function of applied in-plane loads (Nxx, Nyy and Nxy) as well as the fiber orientation angle $\theta$. If the in-plane loads are satisfied the design optimization procedure reduces the finding $\theta$ for which the objective function is minimum.

\subsection{Elastic Properties of a Lamina}

Longitudinal Modulus

$$
E_{22}=\frac{E_{f} E_{m}}{E_{m} V_{f}+E_{f} V_{m}}
$$

Transverse Modulus

$$
E_{11}=E_{f} V_{f}+E_{m} V_{m}
$$

Major Poisson's Ratio

$$
\mu_{12}=\mu_{f} V_{f}+\mu_{m} V_{m}
$$$$
\mu_{21}=\frac{E_{22}}{E_{11}} \mu_{12}
$$

Minor Poisson's Ratio

$$
G_{12}=\frac{G_{f} G_{m}}{G_{f} V_{m}+G_{m} V_{f}}
$$

\subsubsection{Continuous Fiber Angle-Ply Lamina}

$\frac{1}{E_{X X}}=\frac{\cos ^{4} \theta}{E_{11}}+\frac{\sin ^{4} \theta}{E_{22}}\left[\frac{1}{G_{12}}-\frac{2 \mu}{E_{11}}\right] \sin ^{2} \theta \cos ^{2} \theta$

$\frac{1}{E_{y y}}=\frac{\sin ^{4} \theta}{E_{11}}+\frac{\cos ^{4} \theta}{E_{22}}\left[\frac{1}{G_{12}}-\frac{2 \mu}{E_{11}}\right] \sin ^{2} \theta \cos ^{2} \theta$

$\mu_{x y}=E_{X X}\left[\frac{\mu_{12}}{E_{11}}\left[\sin ^{4} \theta+\cos ^{4} \theta\right]\right]-\left[\frac{1}{E_{X X}}+\frac{1}{E_{y y}}-\frac{1}{G_{12}}\right] \sin \theta \cos \theta$

$\frac{1}{G_{x y}}=2\left[\frac{2}{E_{11}}+\frac{2}{E_{22}}+\frac{4 \mu_{12}}{E_{11}}-\frac{1}{G_{12}}\right] \sin ^{2} \theta \cos ^{2} \theta+\frac{1}{G_{12}}\left[\sin ^{4} \theta+\cos ^{4} \theta\right]$

\subsection{Preliminary Design}

The present composite shell is air cylinder (air receiver) pressure vessel. A thin- walled circular cylindrical shell of radius $\mathrm{R}$ loaded with internal pressure $\mathrm{p}$ and axial forces are uniformly distributed over the end cross-section contours. The overall dimensions are $1470 \mathrm{~mm}$ with dishes, and $1030 \mathrm{~mm}$ length of mid section, and $670 \mathrm{~mm}$ of outer diameter and shell thickness is $10 \mathrm{~mm}$, working pressure is $30 \mathrm{bar}$, i.e; $3 \mathrm{~N} / \mathrm{mm}^{2}$ or $3 \mathrm{MPa}$. Applying the equilibrium condition in the axial direction $\Pi R^{2} \mathrm{p}=2 \Pi R q$ Circumferential stress $\sigma_{c}$, axial stress $\sigma_{a}$, stress which can be calculated as ' $h$ ' is the wall thickness. Let $\mathrm{p}$ is the burst pressure $\bar{p}$ and $\bar{\sigma}$ be the material ultimate tensile stress.

$$
\begin{array}{ll}
\text { Circumferential stress } & \sigma_{c}=\frac{p R}{h} \\
\text { Axial stress } & \sigma_{a}=\frac{p R}{2 h}
\end{array}
$$

$$
\text { Wall thickness } \quad h=\frac{p \bar{R}}{\bar{\sigma}}
$$

\subsection{Stresses and strains of composite shell}

The Stress Strain Relation of a composite lamina may be written in the following matrix form where the $\mathrm{Q}_{\mathrm{ij}}$ are defined in terms of lamina, Young's modulus and Poisson's ratio as follows:

$$
\begin{array}{rlrl}
Q_{11} & =\frac{E_{11}}{1-\mu_{12} \mu_{21}} & Q_{22}=\frac{E_{22}}{1-\mu_{12} \mu_{21}} & Q_{12}=\frac{\mu_{12} E_{11}}{1-\mu_{12} \mu_{21}} \\
\mu_{21}=\mu_{12} \frac{E_{22}}{E_{11}} & Q_{66}=Q_{12} & Q_{16}=Q_{26}
\end{array}
$$

The terms within $[\mathrm{Q}]$ are defined to be

$$
\begin{aligned}
& \bar{Q}_{11}=Q_{11} \cos ^{4} \theta+2\left(Q_{12}+2 Q_{66}\right) \sin ^{2} \theta \cos ^{2} \theta+Q_{22} \sin ^{4} \theta \\
& \bar{Q}_{22}=Q_{11} \sin ^{4} \theta+2\left(Q_{12}+2 Q_{66}\right) \sin ^{2} \theta \cos ^{2} \theta+Q_{22} \cos ^{4} \theta \\
& \bar{Q}_{12}=\left(Q_{11}+Q_{22}+2 Q_{12}\right) \sin ^{2} \theta \cos ^{2} \theta+Q_{66}\left(\sin ^{4} \theta+\cos ^{4} \theta\right) \\
& \bar{Q}_{66}=\left(Q_{11}+Q_{22}-2 Q_{12}-2 Q_{66}\right) \sin ^{2} \theta \cos ^{2} \theta+Q_{66}\left(\sin ^{4} \theta+\cos ^{4} \theta\right) \\
& \bar{Q}_{16}=\left(Q_{11}-Q_{22}-2 Q_{66}\right) \sin \theta \cos ^{3} \theta+\left(Q_{11}-Q_{22}+2 Q_{66}\right) \sin ^{3} \theta \cos \theta \\
& \bar{Q}_{26}=\left(Q_{11}-Q_{12}-2 Q_{66}\right) \sin ^{3} \theta \cos \theta+\left(Q_{12}-Q_{22}+2 Q_{66}\right) \sin \theta+\cos ^{3} \theta \\
& \ldots .(3.10)
\end{aligned}
$$

Combining these relations and arranged in a matrix form as shown in equation 3.11

$$
\left[\begin{array}{l}
\sigma_{x} \\
\sigma_{y} \\
\tau_{x y}
\end{array}\right]=\left[\begin{array}{lll}
\bar{Q}_{11} & \bar{Q}_{12} & \bar{Q}_{13} \\
\bar{Q}_{21} & \bar{Q}_{22} & \bar{Q}_{23} \\
\bar{Q}_{31} & \bar{Q}_{32} & \bar{Q}_{33}
\end{array}\right]_{k}\left[\begin{array}{c}
\varepsilon_{x} \\
\varepsilon_{y} \\
\varepsilon_{x y}
\end{array}\right]_{k}+Z_{k}\left[\begin{array}{lll}
\bar{Q}_{11} & \bar{Q}_{12} & \bar{Q}_{13} \\
\bar{Q}_{21} & \bar{Q}_{22} & \bar{Q}_{23} \\
\bar{Q}_{31} & \bar{Q}_{32} & \bar{Q}_{33}
\end{array}\right]_{k}\left[\begin{array}{c}
k_{x} \\
k_{y} \\
k_{x y}
\end{array}\right]_{k}
$$

The same relationship is expressed in more compact form below

$$
[\sigma]_{k}=[\bar{Q}]_{k}\left[\varepsilon^{0}\right]+Z_{k}[\bar{Q}]_{k}[k]
$$

To combine the lamina stiffness it is necessary to invoke the definition of stress and moment resultant, $\mathrm{N}$ and $\mathrm{M}$ as integral of Stress through the thickness of the lamina. The overall stiffness properties of a composite lamina may now be expressed via the following matrix equation. Where the $A_{i j}$, $B_{i j}$ and $D_{i j}$ are summation of lamina stiffness values, defined as shown. 
$\left[\begin{array}{l}N_{x} \\ N_{y} \\ N_{x y}\end{array}\right]=\left[\begin{array}{ccc}A_{11} & A_{12} & A_{13} \\ A_{21} & B A_{22} & A_{23} \\ A_{31} & A_{32} & A_{33}\end{array}\right]\left[\begin{array}{l}\varepsilon_{x}^{0} \\ \varepsilon_{y}^{0} \\ \varepsilon_{x y}^{0}\end{array}\right]+\left[\begin{array}{ccc}B_{11} & B_{12} & B_{13} \\ B_{21} & B_{22} & B_{23} \\ B_{31} & B_{32} & B_{33}\end{array}\right]\left[\begin{array}{l}k_{x} \\ k_{y} \\ k_{x y}\end{array}\right]$

$\left[\begin{array}{l}M_{x} \\ M_{y} \\ M_{x y}\end{array}\right]=\left[\begin{array}{lll}B_{11} & B_{12} & B_{13} \\ B_{21} & B_{22} & B_{23} \\ B_{31} & B_{32} & B_{33}\end{array}\right]\left[\begin{array}{l}\varepsilon_{x}^{0} \\ \varepsilon_{y}^{0} \\ \varepsilon_{x y}^{0}\end{array}\right]+\left[\begin{array}{ccc}D_{11} & D_{12} & D_{13} \\ D_{21} & D_{22} & D_{23} \\ D_{31} & D_{32} & D_{33}\end{array}\right]\left[\begin{array}{l}k_{x} \\ k_{y} \\ k_{x y}\end{array}\right]$

.... (3.13)

Each component of the $[\mathrm{A}],[\mathrm{B}]$ and $[\mathrm{D}]$ matrices is defined by ....(3.14)

$$
\left.\begin{array}{rl}
A_{i j} & =\sum_{k=1}^{n}\left(\overline{Q_{i j}}\right)\left(h_{k}-h_{k-1}\right) \\
B_{i j} & =\frac{1}{2} \sum_{k=1}^{n}\left(\overline{Q_{i j}}\right)\left(h_{k}^{2}-h_{k-1}^{2}\right) \\
D_{i j} & =\frac{1}{3} \sum_{k=1}^{n}\left(\overline{Q_{i j}}\right)\left(h_{k}^{3}-h_{k-1}^{3}\right) \\
{\left[\mathrm{A}^{*}\right]} & =\mathrm{A}^{-1} \\
{\left[\mathrm{~B}^{*}\right]} & =\left[\mathrm{A}^{-1}\right][\mathrm{B}] \\
{\left[\mathrm{C}^{*}\right]} & =[\mathrm{B}]\left[\mathrm{A}^{-1}\right]=\left[\mathrm{B}^{*}\right]^{T} \\
{\left[\mathrm{D}^{*}\right]} & =[\mathrm{D}]-[\mathrm{B}]\left[\mathrm{A}^{-1}\right][\mathrm{B}] \\
{\left[\mathrm{A}^{1}\right]} & =\left[\mathrm{A}^{*}\right]-\left[\mathrm{B}^{*}\right]\left[\mathrm{D}^{*-1}\right]\left[\mathrm{C}^{*}\right]=\left[\mathrm{A}^{*}\right]+\left[\mathrm{B}^{*}\right]\left[\mathrm{D}^{*-1}\right]\left[\mathrm{B}^{*}\right]^{\mathrm{T}} \\
{\left[\mathrm{B}^{1}\right]} & =\left[\mathrm{B}^{*}\right]\left[\mathrm{D}^{*-1}\right] \\
{\left[\mathrm{C}^{1}\right]} & =\left[\mathrm{D}^{*-1}\right]\left[\mathrm{C}^{*}\right]=\left[\mathrm{B}^{1}\right]^{\mathrm{T}}=\left[\mathrm{B}^{1}\right] \\
{\left[\mathrm{D}^{1}\right]} & =\left[\mathrm{D}^{*-1}\right] \\
\hline \varepsilon \\
\mathrm{E}
\end{array}\right]=\left[\begin{array}{l}
\mathrm{A}^{1} \quad \mathrm{~B}^{1} \\
\left.\mathrm{~B}^{1} \quad \mathrm{D}^{1}\right]\left[\begin{array}{l}
\mathrm{N} \\
\mathrm{M}
\end{array}\right]
\end{array}\right.
$$

In the above equations, the $\mathrm{A}_{\mathrm{ij}}$ are the extension stiffness terms, the $D_{i j}$ are the bending stiffness, and $B_{i j}$ represent stiffness coupling between extension and bending. The $A_{16,26}$ ,further represent coupling between extension and shear, While the $\mathrm{D}_{16,26}$,Terms indicate coupling between bending and twisting. The existence of these coupling terms indicates in general the possibility of some "peculiar" behavior in composites in as compared to isotropic metal structures. For example, it is possible to obtain both twisting and shearing (as well as extension) in a composite panel subjected to purely membrane extension loads. It is also possible to obtain negative Poisson's ratios. Often it is desirable to construct laminates which minimize these coupling phenomena, but such behavior may also be beneficial in suppressing some buckling failure modes. If the laminate is mid plane symmetric that is each ply has a twin (same angle) located the same distance from the mid-plane, the Bij term disappear.

\subsection{Analytical Buckling Solution for FRP Composite Shell}

Design analysis of a structure or a component is performed by comparing stress (strain) due to applied loads with the allowable strength (or strain capacity) of the material. In case of biaxial or multi axial stress fields a suitable failure theory is used for this comparison. Many failure theories have been proposed for fiber reinforced composites. Some of them are
(A)Maximum Stress theory
(B)Maximum Strain theory
(C)Azzi - T sai - Hill theory
(D) Tsai - Wu stress theory
(E) Tsai - Wu strain theory

Failure: Every material has certain strength Expressed in terms of stress and strain, Beyond which it fractures or fails to carry the load.

\section{Why need Failure Theories:}

(a) To design Structural components and calculate margin of safety.

(b) To guide in materials development.

(c) To determine weak and strong directions

It is possible that the shell may fail materially before the buckling conditions are reached. A check can be made at each load step to detect the first occurrence of failure, the first ply failure (FPF). Before applying the theories of failure in the lamina, applied stresses (or strains) are first transformed into principal material directions using the equations.

Maximum Stress Theory: Failure occurs when at least one stress component along the principal material axes exceeds the corresponding strength in that direction.

Maximum Strain Theory: Failure occurs when at least one of the strain components along the principal material axis exceeds that of the ultimate strain in that direction.

Tsai-Hill Theory: Hill extended the von Mises criterion for ductile anisotropic material.

Azzi-Tsai extended this theory to anisotropic fiber reinforced composites. Failure occurs

When the following equation is equal to or greater than one.

$$
\mathrm{A} \sigma 21+\mathrm{B} \sigma 22+\mathrm{C} \sigma 1 \sigma 2+\mathrm{D} \tau 26=1
$$


The object of buckling analysis is to estimate the maximum pressure that the composite shell can withstand before it becomes elastically unstable.

Windenburg and Trilling Equation: The equation can be used for thin wall filament wound structures with conventional sheet materials. "Windenburg and Trilling Equation" is used to determine composite shell composite shell critical buckling pressure

Pcr $=$ Critical Pressure, $\mathrm{t}=$ Thickness of the Shell,

$\mathrm{d}=$ Diameter of the cylindrical shell

$\mathrm{L}=$ length (spacing) between the stiffeners, $\mathrm{E}=$ Young's Modulus, $\mu=$ Poisson's Ratio

$$
\begin{aligned}
P_{c r}= & \frac{2.42 E\left[\frac{t}{d}\right]^{2.5}}{\left[1-\mu^{2}\right]^{0.75}\left[\frac{l}{d}-0.45\left[\frac{t}{d}\right]^{0.5}\right]} \\
E_{x}= & \frac{E_{L}}{\cos ^{4} \theta+\frac{E_{L}}{E_{T}} \sin ^{4} \theta+0.25\left[\frac{E_{L}}{E_{T}}-2 \mu\right] \sin ^{2}(2 \theta)} \\
E_{y}= & \frac{E_{L}}{\sin ^{4} \theta+\frac{E_{L}}{E_{T}} \cos ^{4} \theta+0.25\left[\frac{E_{L}}{E_{T}}-2 \mu\right] \sin ^{2}(2 \theta)}
\end{aligned}
$$

\subsubsection{Critical Pressure of Glass Epoxy at an Angle of} $45^{\circ}$

The wall of the cylindrical shell subjected to an internal pressure has to withstand tensile stresses of the following types

(a) Circumferential (or) Hoop stresses

(b) (b) Longitudinal stresses

Circumferential Stresses are stresses acting tangential to Circumference (along the diameter $\mathrm{X}-\mathrm{X}$ ) of the shell, considering the ring stiffeners around the cylinder, so Young's modulus along Hoop direction is calculated.

$\mathrm{EL}=$ Longitudinal Modulus, $\mathrm{ET}=$ Transverse Modulus, $\mu=$ Poisson's Ratio

$$
\begin{aligned}
& E_{L}=60 G P a, E_{T}=12 G P a, \mu=0.3 \\
& E_{x}=\frac{60 \times 10^{3}}{\cos ^{4}\left(45^{\circ}\right)+\frac{60}{12} \sin ^{4}\left(45^{\circ}\right)+0.25\left[\frac{60}{12}-2 \times 0.3\right] \sin ^{2}\left(2 \times 45^{\circ}\right)} \\
& =\frac{60 \times 10^{3}}{2.6}=23076.92 \\
& P_{c r}=\frac{2.42 E\left[\frac{t}{d}\right]^{2.5}}{\left[1-\mu^{2}\right]^{0.75}\left[\frac{l}{d}-0.45\left[\frac{t}{d}\right]^{0.5}\right]} \\
& P_{c r}=\frac{2.42 \times 23076.92\left[\frac{10}{670}\right]^{2.5}}{\left[1-0.3^{2}\right]^{0.75}\left[\frac{343}{670}-0.45\left[\frac{10}{670}\right]^{0.5}\right]}=3.5908
\end{aligned}
$$

\subsubsection{Critical Pressure of Carbon Epoxy at an Angle of $45^{\circ}$ :}

$\mathrm{E}_{\mathrm{L}}=$ Longitudinal Modulus, $\mathrm{ET}=$ Transverse Modulus, $\mu=$ Poisson's Ratio

$$
\begin{aligned}
E_{L}= & 130 G P a, E_{T}=11 G P a, \mu=0.27 \\
E_{x}= & \frac{130 \times 10^{3}}{\cos ^{4}\left(45^{\circ}\right)+\frac{130}{11} \sin ^{4}\left(45^{\circ}\right)+0.25\left[\frac{130}{11}-2 \times 0.27\right] \sin ^{2}\left(2 \times 45^{\circ}\right)} \\
& =\frac{130 \times 10^{3}}{4.6142}=28173.89
\end{aligned}
$$

$$
\begin{aligned}
& P_{c r}=\frac{2.42 \times 28173.89\left[\frac{10}{670}\right]^{2.5}}{\left[1-0.27^{2}\right]^{0.75}\left[\frac{343}{670}-0.45\left[\frac{10}{670}\right]^{0.5}\right]} \\
& P_{c r}=3.872
\end{aligned}
$$

\subsubsection{Critical Pressure of Aramid Epoxy at an Angle}

of $45^{\circ}$ :

$\mathrm{E}_{\mathrm{L}}=$ Longitudinal Modulus, ET $=$ Transverse Modulus, $\mu=$ Poisson's Ratio

$$
\begin{gathered}
E_{L}=90 G P a, E_{T}=5 G P a, \mu=0.34 \\
E_{x}=\frac{90 \times 10^{3}}{\cos ^{4}\left(45^{\circ}\right)+\frac{90}{5} \sin ^{4}\left(45^{\circ}\right)+0.25\left[\frac{90}{5}-2 \times 0.34\right] \sin ^{2}\left(2 \times 45^{\circ}\right)} \\
=\frac{90 \times 10^{3}}{9.08}=9911.89
\end{gathered}
$$




$$
\begin{aligned}
P_{c r}= & \frac{2.42 \times 9911.89\left[\frac{10}{670}\right]^{2.5}}{\left[1-0.34^{2}\right]^{0.75}\left[\frac{343}{670}-0.45\left[\frac{10}{670}\right]^{0.5}\right]} \\
P_{c r}=1.5756 &
\end{aligned}
$$

\subsection{Theoretical Calculations}

The Weight and volume fractions can be calculated using the following equations

a) Calculation of Volume fraction: The volume of fiber in a cured composite. The fiber volume of a composite material may be determined by chemical matrix digestion, in which the matrix is dissolved and the fibers weighed. Typical values for glass/epoxy and for graphite/epoxy, based upon the fiber type, are $55-67 \%$ fiber.

$V_{f}=$ volume fraction of fibers,

$W_{f}=$ weight of fibers, $W_{m}=$ weight of matrix

$\rho_{f}=$ density of fibers,$\rho_{m}=$ density of matrix

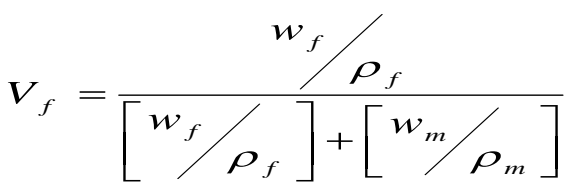

$W_{f}=\frac{V_{f} \rho_{f}}{\left[V_{f} \rho_{f}\right]+\left[V_{m} \rho_{m}\right]}$

$W_{f}=0.65, W_{m}=0.35, \rho_{f}=2500, \rho_{m}=1611$

$V_{f}=\frac{0.65 / 2500}{[0.65 / 2500]+[0.35 / 1611]}=0.55 \mathrm{~m}^{3}$

$V_{m}=1.0-0.55=0.45 m^{3}$

\section{b) Calculation of Density:}

Density defined in a qualitative manner as the measure of the relative "heaviness" of objects with a constant volume.

(Density $=$ mass $/$ volume).

It is usually expressed in $\mathrm{kg} / \mathrm{m}^{\wedge} 3$.

The Density of the composite for the given volume fraction is

$$
\rho_{c}=\rho_{f} V_{f}+\rho_{m} V_{m}
$$

$=2500 \times 0.55+1611 \times 0.45=2100 \mathrm{~kg} / \mathrm{m}^{3}$

c) Calculation of Elastic Properties of the composite:

Modulus of Elasticity: The ratio of the stress applied to a body to the strain that results in the body in response to it.
(OR)The ratio of the longitudinal strain to the longitudinal stress is called young's modulus.

The modulus of elasticity is calculated as follows

Longitudinal Modulus

$$
\begin{aligned}
& E_{11}=E_{f} V_{f}+E_{m} V_{m} \\
& \quad=106.30 \times 0.55+3.4 \times 0.45=60 G P a
\end{aligned}
$$

\section{Transverse Modulus}

$$
\begin{aligned}
E_{22} & =\frac{E_{f} E_{m}}{E_{m} V_{f}+E_{f} V_{m}} \\
& =\frac{106.30 \times 3.4}{3.4 \times 0.55+106.30 \times 0.45}=7.3 \mathrm{GPa}
\end{aligned}
$$

\section{d) Major Poisson's Ratio}

Poisson's ratio is the ratio of transverse contraction strain to longitudinal extension strain in the direction of stretching force. Tensile deformation is considered positive and compressive deformation is considered negative. The definition of Poisson's ratio contains a minus sign so that normal materials have a positive ratio. Poisson's ratio, also called Poisson coefficient, is usually represented as $\mu$.

$$
\begin{aligned}
& \mu_{12}=\mu_{f} V_{f}+\mu_{m} V_{m} \\
& =(0.26 \times 0.55)+(0.33 \times 0.45)=0.2915
\end{aligned}
$$

\section{Minor Poisson's Ratio}

$$
\begin{aligned}
& \mu_{21}=\frac{E_{22}}{E_{11}} \mu_{12} \\
& =\frac{7.3}{60} \times 0.2915=0.035
\end{aligned}
$$

\section{e) Shear Modulus}

Shear modulus or modulus of rigidity is defined denoted by, $\mathrm{G}$, Is defined as the shear stress to shear strain, it is usually expressed in gigapascals (GPa), Shear Modulus is always Positive.

$$
\begin{aligned}
G_{12} & =\frac{G_{f} G_{m}}{G_{f} \mu_{m}+G_{m} \mu_{f}} \\
\text { Where } G_{f} & =\frac{E_{f}}{2\left(1+\mu_{f}\right)}=\frac{106.30}{2(1+0.26)}=42.182 \mathrm{GPa} \\
G_{m} & =\frac{E_{m}}{2\left(1+\mu_{m}\right)}=\frac{3.4}{2(1+0.33)}=1.278 \mathrm{GPa} \\
G_{12} & =\frac{(42.82 \times 1.278)}{(42.82 \times 0.33)+(1.278 \times 0.26)}=3.783 \mathrm{GPa}
\end{aligned}
$$




\subsection{Properties of Composites}

Table.2.1.Properties of Composites

\begin{tabular}{|c|c|c|c|}
\hline Properties & $\begin{array}{c}\text { Glass } \\
\text { Epoxy }\end{array}$ & $\begin{array}{c}\text { Carbon } \\
\text { Epoxy }\end{array}$ & $\begin{array}{c}\text { Aramid } \\
\text { Epoxy }\end{array}$ \\
\hline Fibervolume fraction, & 0.55 & 0.55 & 0.55 \\
\hline Vensity, p (kg/m3) & 2100 & 1500 & 1320 \\
\hline $\begin{array}{c}\text { Longitudinal modulus } \\
\text { E1 (Gpa) }\end{array}$ & 60 & 130 & 90 \\
\hline $\begin{array}{c}\text { Transverse modulus } \\
\text { E2 (Gpa) }\end{array}$ & 7.3 & 11 & 5 \\
\hline $\begin{array}{c}\text { Shear modulus } \\
\text { G12 (Gpa) }\end{array}$ & 3.78 & 5.5 & 1.8 \\
\hline $\begin{array}{c}\text { Poisson's Ratio } \mu 12 \\
\text { Longitudinal tensile } \\
\text { strength } 61 \text { (Mpa) }\end{array}$ & 1750 & 2200 & 2500 \\
\hline $\begin{array}{c}\text { Transverse tensile } \\
\text { strength } 62 \text { (Mpa) }\end{array}$ & 40 & 50 & 30 \\
\hline $\begin{array}{c}\text { In-plane shear strength } \\
\tau 12 \text { (Mpa) }\end{array}$ & 60 & 70 & 30 \\
\hline
\end{tabular}

\subsection{WEIGHT CALCULATIONS}

The days are long gone when it was considered that the heavier the product better the quality. The light weight composite component makes more desirable to manufacturers, as well as consumers and workers. Composite materials include outstanding Strength, excellent durability, High heat resistance and significant weight reduction. The present work clearly emphasizes on the usage of composite materials in the production of cylindrical pressure vessels. Weight calculations have been carried out by varying the materials like conventional and composite materials, to find out the material that has minimum weight. Carbon fiber Composites are roughly quarter weight of the st

Length (height ' $h$ ') of the cylinder $L=1030 \mathrm{~mm}$

Diameter of the cylinder $\mathrm{d}=670 \mathrm{~mm}$

Thickness of the shell $\mathrm{t}=10 \mathrm{~mm}$

$$
\begin{aligned}
& \mathrm{R}-\mathrm{r}=\mathrm{t} \\
& \mathrm{r}=\mathrm{R}-\mathrm{t} \\
& \mathrm{r}=335-10 \\
& \mathrm{r}=325 \mathrm{~mm}
\end{aligned}
$$

$$
\begin{aligned}
\text { Volume } & =\Pi \mathrm{r}^{2} \mathrm{~h} \\
& =\Pi \times\left(335^{2}-325^{2}\right) \times 1030 \\
& =21356546.86 \mathrm{~mm}^{3} \\
& =21.356546 \times 10^{6} \mathrm{~mm}^{6} \\
= & 21.356546 \times 10^{-3}
\end{aligned}
$$

Density $\rho=$ mass / Volume

Weight $=\mathrm{m} \cdot \mathrm{g}=\rho \cdot \mathrm{v} \cdot \mathrm{g}$

Density of steel $=7.86 \mathrm{gm} / \mathrm{cm}^{3}=7.86 \times 10^{3}$

$\mathrm{m}=\rho \mathrm{V}=7.86 \times 21.356 \times 10^{-3}=167.858 \mathrm{~kg}$

\section{Glass Epoxy}

$2.1 \times 10^{3} \times 21.356 \times 10^{-3}=44.847 \mathrm{~kg}$

\section{Carbon Epoxy}

$$
1.55 \times 10^{3} \times 21.356 \times 10^{-3}=33.10 \mathrm{~kg}
$$

Aramid Epoxy

$1.32 \times 10^{3} \times 21.356 \times 10^{-3}=28.189 \mathrm{~kg}$

\section{STATIC ANALYSIS AND BUCKLING ANALYSIS OF FEM \\ 3.1 INTRODUCTION TO FINITE ELEMENT METHOD}

The finite element method is a numerical procedure for analyzing structures and continua. Usually problem addressed is too complicated to solve satisfactorily by classical analytical methods. The finite element procedure develops many simultaneous algebraic equations, which are generated and solved on a digital computer. The results obtainable are accurate enough for engineering purposes at reasonable cost. In addition it is an efficient design tool by which designers can perform parametric design studies by considering various design cases(different shapes, materials, loads , etc.,), analyze them and choose the optimum design. Hence the method has increasingly gained popularity among both researchers and practitioners.

\subsection{GENERAL DESCRIPTION OF FINITE ELEMENT ANALYSIS}

In the finite element method, the actual continuum or body of matter like solid, liquid or gas is represented as on assemblage of sub divisions called finite elements. These elements are considered to be interconnected at specified joints, which are called nodes or nodal points. The nodes usually lie on the element boundaries where adjacent elements are considered to be connected. Since the actual variation of the field variable (like displacement, stress, temperature, pressure and velocity) inside the continuum is not known, we assume that the variation of field variable inside a finite element can be approximated by a simple function. These approximating functions (also called interpolation models) are defined in terms of values at the nodes. When field equations (like equilibrium equations) for the whole continuum are written. The new unknown will be the nodal values of the field variable. By solving the field equations, which are generally in the form of matrix equations, the nodal values of the field variable will be known. Once these are known, the approximating function defines the field variable throughout the assemblage of elements.

\subsection{BASIC STEPS OF FINITE ELEMENT}

\section{ANALYSIS}

There are three basic steps involved in this procedure

1) Pre Processor (Building the model (or) Modeling) 
2) Solution (Applying loads and solving)

3) Post Processor (Reviewing the results)

\section{Preprocessor (defining the problem)}

The problem is defined through mathematical modeling or analytical modeling. The formulation of the set of mathematical equations that models the physical problem within the scale and accuracy required by the application. The following steps are involved in preprocessor

- Define key point/lines/ areas/volumes

- Define element type and material/ geometric properties

- Mesh lines/ areas / volumes are required.

Solution (assigning loads, constraints and solving)

Here the loads (points load, uniformly distribute load, force or pressure), constraints (translational or rotational) are specified and finally solve the resulting set of equations.

\section{Post Processor}

The numerical results in terms of their mathematical and physical significance are interpreted. In this stage, further processing and viewing of the results cab be done such as

- List of nodal displacements

- Element forces and moments

- Deflection plots

- Stress contour diagrams

\subsection{ELEMENTS USED FOR ANALYSIS}

In Ansys (finite element analysis software) different types of elements are used depending on the problem nature and the type of analysis to be performed. The element chosen characterizes among other things, the degree of freedom set (displacements and/ or rotations, temperatures, etc.), the characteristic shape of the element (line, quadrilateral, brick, etc.), whether the element lies in 2-D space or 3 - D space, response of the system. The elements used in Ansys are classified as shown in table 4.1 below.
Table.3.1 List of Elements by Classification

\begin{tabular}{|c|c|c|}
\hline & & ELEMENTS \\
\hline Structural Point & & MASS21 \\
\hline \multirow[t]{2}{*}{ Structural Lime } & $2-D$ & LINK1 \\
\hline & $3-\mathrm{D}$ & LINK8, LINK10, LINK11, LINK180 \\
\hline \multirow[t]{2}{*}{ Structural Beam } & $2-\mathrm{D}$ & BEAM13, BEAM23, BEAM154 \\
\hline & $3-\mathrm{D}$ & BEAM4, BEAM24, BEAM44, BEAM188, BEAM189 \\
\hline \multirow[t]{2}{*}{ Structural Solid } & 2-D & $\begin{array}{l}\text { PLANE2, PLANE25, PLANE42, PLANES2, PLANE83, } \\
\text { PLANE145, } \\
\text { PLANE146, PLANE182, PLANE183 }\end{array}$ \\
\hline & $3-\mathrm{D}$ & $\begin{array}{l}\text { SOLID } 45, \text { SOLID } 64, \text { SOLID } 65, \text { SOLID } 92, \text { SOLID } 95, \\
\text { SOLID } 147, \\
\text { SOLID } 148, \text { SOLID } 185, \text { SOLID } 186, \text { SOLID } 187\end{array}$ \\
\hline \multirow[t]{2}{*}{ Structural Shell } & $2-D$ & SHELL51,SHELL61, SHELL 208, SHELL 209 \\
\hline & $3-\mathrm{D}$ & $\begin{array}{l}\text { SHELL } 28, \text { SHELL } 41, \text { SHELL } 43, \text { SHELL } 63, \text { SHELL } 93 \text {, } \\
\text { SHELL } 143 \text {, } \\
\text { SHELL } 150, \text { SHELL } 181\end{array}$ \\
\hline Structural Solid Shell & $3-\mathrm{D}$ & SOLSH 190 \\
\hline Structural pipe & & PIPE16,PIPE17,PIPE18,PIPE 20,PIPE59,PIPE60 \\
\hline Structural Interface & & INTER192,INTER193,INTER194,INTER195 \\
\hline $\begin{array}{l}\text { Structural Multipoint } \\
\text { Constraint Elements }\end{array}$ & & $\mathrm{MPCI} 184$ \\
\hline $\begin{array}{l}\text { Structural Layered } \\
\text { Composite }\end{array}$ & & SOLID 46, SHELL91, SHELL99, SOLID191 \\
\hline Hyper Elastic Solid & & $\begin{array}{l}\text { HYPER } 56, \text { HYPER } 58, \text { HYPER } 74, \text { HYPER } 44 \text {, HYPER } 66 \text {, } \\
\text { HYPER } 158\end{array}$ \\
\hline Thermal Line & & LINK31, LINK32, LINK33, LINK34 \\
\hline \multirow[t]{2}{*}{ Thermal Solid } & $2-\mathrm{D}$ & PLANE35,PLANE55,PLANE75,PLANE77,PLANE78 \\
\hline & $3-\mathrm{D}$ & SOLID 70,SOLID87,SOLID90 \\
\hline Thermal Shell & & SHELL 57, SHELL 131, SHELL 132 \\
\hline
\end{tabular}

\subsubsection{SOLID 46 ELEMENT DESCRIPTION}

SOLID46 is a layered version of the 8-node structural solid element designed to model layered thick shells or solids. The element allows up to 250 different material layers. If more than 250 layers are required, a user-input constitutive matrix option is available. The element may also be stacked as an alternative approach. The element has three degrees of freedom at each node: translations in the nodal $\mathrm{x}, \mathrm{y}$, and $\mathrm{z}$ directions as shown in Fig.4.1. One element per layer issue in solid46 by dividing a given into $\mathrm{N}$ imaginary sub-layers of same orientation and thickness = layer thickness / N. Solid46 is actually useful for modeling sand witched structures with thin layers.
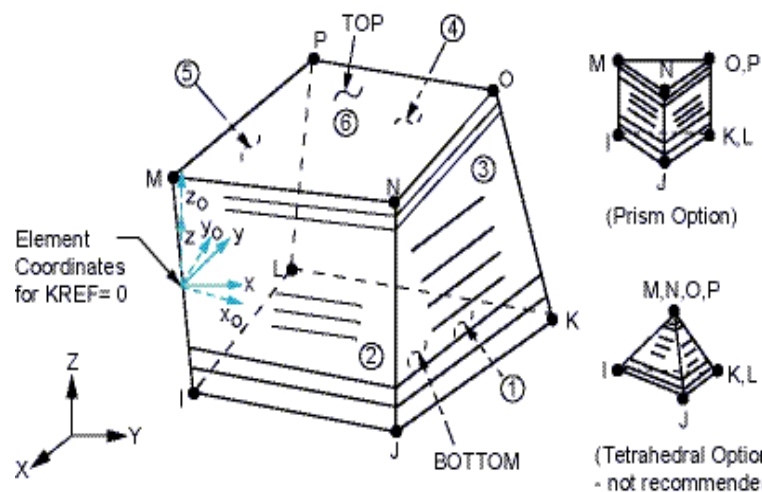

(Prism Option)

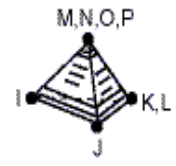

(Tetrahedral Option not recommended)

Fig 3.1 Geometry of Solid - 46 Elements 


\section{a) Specifying Individual Layer Properties:}

The layer configuration is defined layer-by-layer. The bottom layer is designed as layer 1 , and additional layer are stacked from bottom to top in the positive $\mathrm{Z}$ (normal) direction of the element coordinate system. For each layer the following properties are specified in the element real constant table.

\section{b) Number of Layers:}

The total number of layers must be specified. The properties of all layers should be entered. If the properties of the layer are symmetrical about the mid thickness of the element, only half of properties of the layers, up to and including the middle layer (if any), need to be entered.

\section{c) Material Properties:}

The material properties of each layer may be orthotropic in the plane of the element. The properties of Isotropic/orthotropic material i.e. elastic modulus, poisons ratio, shear modulus and density are to be specified. The real constant MAT is used to define the layer material number instead of the element material number. The material $\mathrm{X}$ direction corresponds to the local layer $\mathrm{X}^{1}$ direction.

\section{d) Layer Orientation Angle:}

The local coordinate system for each layer is defined. The layer number can arrange from 1 to 250. In this local righthanded system, the $\mathrm{X}^{\prime}$ - axis is rotated an angle THETA (in degrees) from the $\mathrm{X}$-axis towards the element $\mathrm{y}$ - axis. Different layer orientations are possible depending on the arrangement of laminates of the composite material chosen for analysis.

\section{e) Layer Thickness:}

Each layer of the laminated shell element may have a variable thickness. The thickness is assumed to vary bilinear over the area of the layer, with the thickness input at the corner node locations. If the layer has a constant thickness, all four corner thickness must be input using positive values. The total thickness of each shell element must be less than twice the radius of curvature, and should be less than one-fifth the radius of curvature.

\subsection{ROLE OF FEM IN STRUCTURAL ANALYSIS}

Structural analysis is probably the most common application of the finite element method. The term structural or structure implies not only civil engineering structures such as ship hulls, aircraft bodies and machine housings as well as mechanical components such as pistons, machine parts and tools.

\subsubsection{Types Of Structural Analysis}

Different types of structural analysis are

- Static Analysis

- Model Analysis

- Harmonic Analysis

- Transient Analysis
- Spectrum Analysis

- Buckling Analysis

- Explicit Dynamic Analysis

\subsection{STATIC ANALYSIS}

A static analysis calculates the effects of the study loading conditions on a structure, while ignoring inertia and damping effects, such as those caused by time varying loads. A static analysis can however, include steady inertia loads (such as gravity and rotational velocity), and time varying loads that can be approximated as static equivalent loads (such as static equivalent wind and seismic loads commonly defined in many building codes).

Static analysis is used to determine the displacement, stresses strains and forces in structural components caused by loads that do not include significant inertia and damping effects. Steady loading and response conditions are assumed i.e. the loads and the structures response are assumed to vary slowly with respect to time. The kinds of loading that can be applied in a static analysis include:

- $\quad$ Entirely applied forces and pressures

- $\quad$ Steady static inertial forces (such as gravity (or) rotational velocity)

- Imposed (non-zero) displacements

- Temperatures (for thermal Strain)

- Fluences (for nuclear swelling)

A static analysis can be either linear or nonlinear. All types of nonlinearities are allowed- Like large deformations, plasticity, creep, stress, stiffening contact (gap) elements and hyper elastic elements.

\subsubsection{Overview of Steps in Static Analysis}

The procedure of static analysis involves three main steps

- $\quad$ Build the model

- Apply loads and obtain the solution

- Review the results

\subsection{BUCKLING ANALYSIS}

Buckling analysis is a technique used to determine buckling loads. Critical loads at which the structure becomes unstable and buckled.
- $\quad$ Build Model
- Obtain the static solution
- Obtain the eigen value buckling solution
- Expand the solution
- Review the results

Buckling analysis is a technique used to determine buckling analysis and element type, material properties; boundary conditions are same as for static analysis except the prestress effects are to be included. 
Structural Analysis is probably the most common application of the finite element method provides a means of Optimizing the design with regard to static and buckling load, deformation, weight and material choice. Finite element analysis works to ensure accurate results by combining the designed geometric input with specific boundary condition information that is provided by process.

\subsubsection{Modeling}

In ANSYS terminology, the term model generation usually takes on the narrower meaning of generating the nodes and elements that represent the spatial volume and connectivity of the actual system. The ANSYS program offers you the following approaches to model generation:

3-D model was built for unstiffened and stiffened shell using CATIA Vr18 software. The modeled shell has the following properties:

$\begin{array}{ll}\text { Cylinder diameter } & 670 \mathrm{~mm} \\ \text { Cylinder height } & 1030 \\ \text { Shell thickness } & 10 \mathrm{~mm} \\ \text { Stiffener Cross section } & 8 \times 150 \mathrm{~mm}\end{array}$

The Thin walled composite cylinder is generated. a cylinder with stiffeners spaced periodically. It is used for calculating propagation constant in circumferential directions of the cylindrical shell subjected to circumferential mode.

\subsubsection{MESHING}

The Modeled cylinder was imported to ANSYS for meshing; The solid model was set element attributes, and established meshing controls, you can then turn the ANSYS program loose to generate the finite element mesh. By taking care to meet certain requirements, we can request a "mapped" mesh containing all quadrilaterals, all triangular, or all brick elements. Here the shell was meshed using quadrilateral elements. The mesh size used is $4 \mathrm{~mm}$ for both shell and the stiffeners. The mesh size may be changed depending on the complexity of the problem.

Also increases as the number of elements increases and it requires powered system to solve the problem. Mesh generation is one of the most critical aspects of engineering simulation.

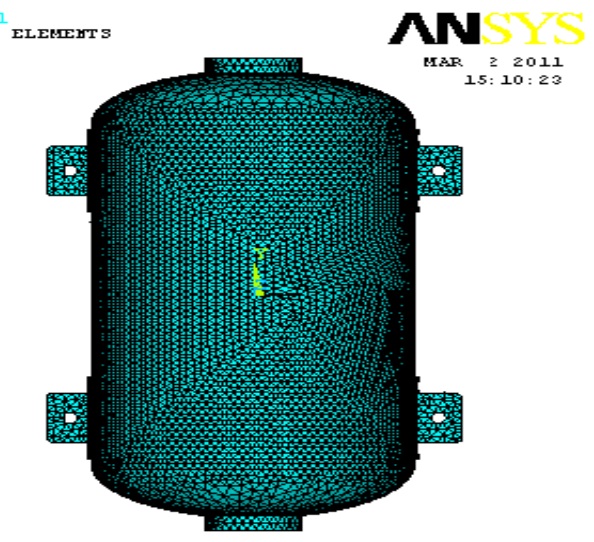

Fig.4.2.Meshed Model

ANSYS meshing technology provides a means to balance these requirements and obtain the right mesh for each simulation in the most automated way possible. The modeled cylinder has a radial symmetry of $45^{\circ}$. Initially one $45^{\circ}$ sector was modeled and then the whole structure was generated using this primary sector. This can be treated as an axi-symmetric problem to reduce the complexity of the problem.

\section{a) Nodes:}

Nodes are the basic building blocks of elements in a mesh. Nodes store elevation and other data set values. Nodes can also be used for building node strings and assigning boundary conditions. The density of mesh nodes helps determine the quality of solution data and can be important to model stability.

\section{b) Mesh Element Types:}

Elements are used to describe the area to be modeled. Elements are formed by joining nodes. The element types supported vary from model to model. Element types include:

- $1 \mathrm{D}$ elements

- Three-node line

- Triangular Elements

- Three-node linear triangle

- Six-node quadratic triangle

- Quadratic (order of solution) Elements

- Eight-node "serendipity" quadrilateral

- Nine-node "Lagrangian" quadrilateral

Water surface and ground elevations are interpolated linearly within each element based on values at the corner nodes. Velocity is interpolated using a quadratic approximation based on values at all the nodes of the element. The quadrilateral elements use identical linear interpolation functions, but their quadratic functions differ because of the presence of an additional node at the center of the nine-node quadrilateral element. 


\subsubsection{Boundary Conditions and Loading}

The global coordinate system of the composite cylindrical shell is defined in such a way that the bottom face of the cylinder lies in the $x-y$ plane and the positive

$\mathrm{Z}$-axis is aligned with the axis of the cylinder. The following boundary conditions were imposed on the composite cylindrical shell.

1. The circumferential and radial displacements ' $\mathrm{v}$ ' and ' $w$ ' respectively equal to zero at both faces of the cylinder (at $\mathrm{z}=0$ and $\mathrm{z}=\mathrm{h}, \mathrm{v}=\mathrm{w}=0$ ).

2. Axial displacement ' $u$ ' is zero at the bottom face of the cylinder but is non-zero at the top face where the load is applied (at $\mathrm{z}=0, \mathrm{u}=0$ and at $\mathrm{z}=\mathrm{h}, \mathrm{u} \neq 0$ ).

A unit force was applied at the upper rim of the cylinder $(\mathrm{z}=\mathrm{h})$ in buckling analysis.

\subsubsection{Solution}

Linear buckling analysis in ANSYS finite-element software is performed in two steps.

1. In the first step a static solution to the composite cylindrical shell is obtained. In this analysis the prebuckling stress of the shell is calculated.

2. The second step involves solving the eigenvalue problem given in the form of Equation. This Equation takes into consideration the prebuckling stress effect matrix $[\mathrm{S}]$ calculated in the first step.

$$
\left([\mathrm{K}]+\lambda_{\mathrm{i}}[\mathrm{S}]\right)\{\psi\}_{\mathrm{i}}=\{0\}
$$

Where

$$
[\mathrm{K}]=\text { stiffness matrix }
$$

$[\mathrm{S}]=$ stress stiffness matrix

$\lambda_{\mathrm{i}}=\mathrm{i}^{\text {th }}$ eigenvalue (used to multiply the loads which generated $[S]$ )

$$
\Psi \mathrm{i}=\text { ith eigenvector of displacements. }
$$

The 'Block Lanczos' method was used to extract the eigenvalues.

The eigenvalues obtained from the buckling analysis are the minimum buckling loads.

\subsubsection{Analysis}

Finite elements analysis was performed on a composite shell without stiffeners having the geometric properties. By obtaining the minimum deformation at maximum load and considering that as a best angle to obtain the minimum buckling load, different analysis were carried out with angleply laminate arrangements, composite materials with different properties as shown in section 4.9. The observations made on this analysis are presented in the results and discussions chapter.

\subsection{COMPOSITE MATERIAL PROPERTIES}

The properties of the composite materials used in the present work are given as below

$$
\text { Glass-Epoxy }
$$

$$
\begin{aligned}
& \mathrm{E}_{1}=60 \mathrm{Gpa} \\
& \mathrm{E}_{2}=7.3 \mathrm{Gpa} \\
& \mathrm{G}_{12}=3.78 \mathrm{Gpa} \\
& \mu_{12}=0.3
\end{aligned}
$$

Carbon-Epoxy

Volume fraction $\mathrm{V}_{\mathrm{f}}=0.55$

$$
\mathrm{E}_{1}=130 \mathrm{Gpa}
$$

$\mathrm{E}_{2}=11 \mathrm{Gpa}$

$\mathrm{G}_{12}=5.5 \mathrm{Gpa}$

$\mu_{12}=0.27$

Aramid-Epoxy

Volume fraction $\mathrm{V}_{\mathrm{f}}=0.55$

$$
\begin{aligned}
& \mathrm{E}_{1}=90 \mathrm{Gpa} \\
& \mathrm{E}_{2}=5 \mathrm{Gpa} \\
& \mathrm{G}_{12}=1.8 \mathrm{Gpa} \\
& \mu_{12}=0.34
\end{aligned}
$$

Volume fraction $\mathrm{V}_{\mathrm{f}}=0.55$

\section{GLASS EPOXY}

\section{Stresses and Deformations at 14 Layers with Different Orientations}

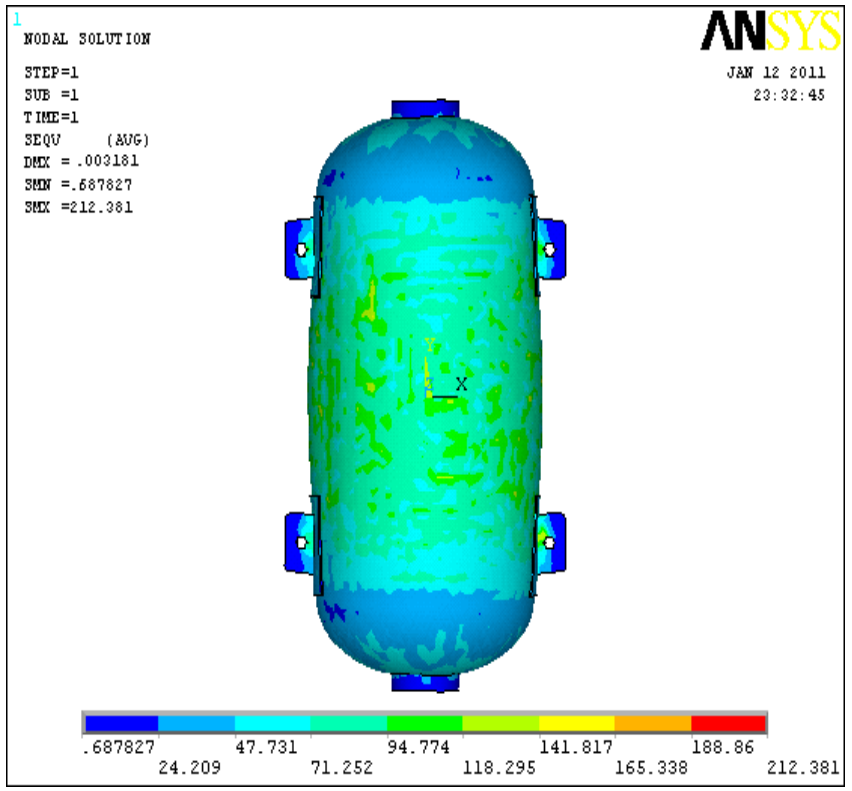

Fig.3.5.(a). $45^{\circ}$ Orientation 


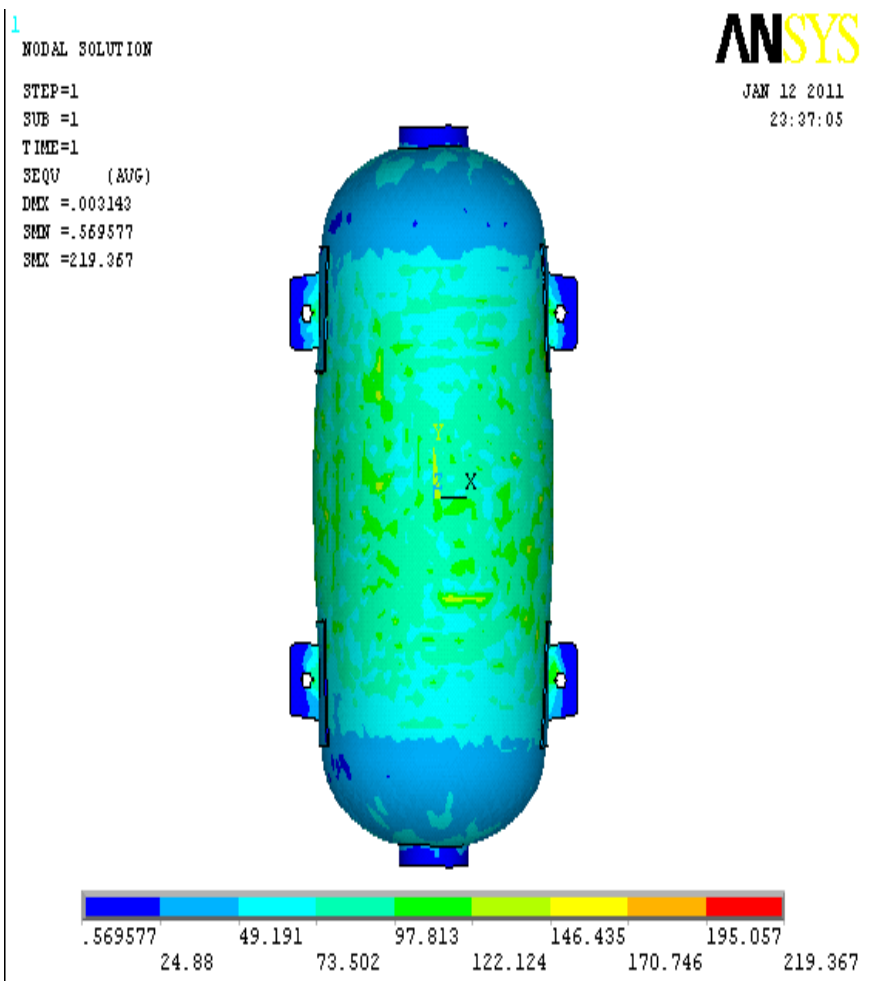

Fig.3.5.(b). $55^{\circ}$ Orientation

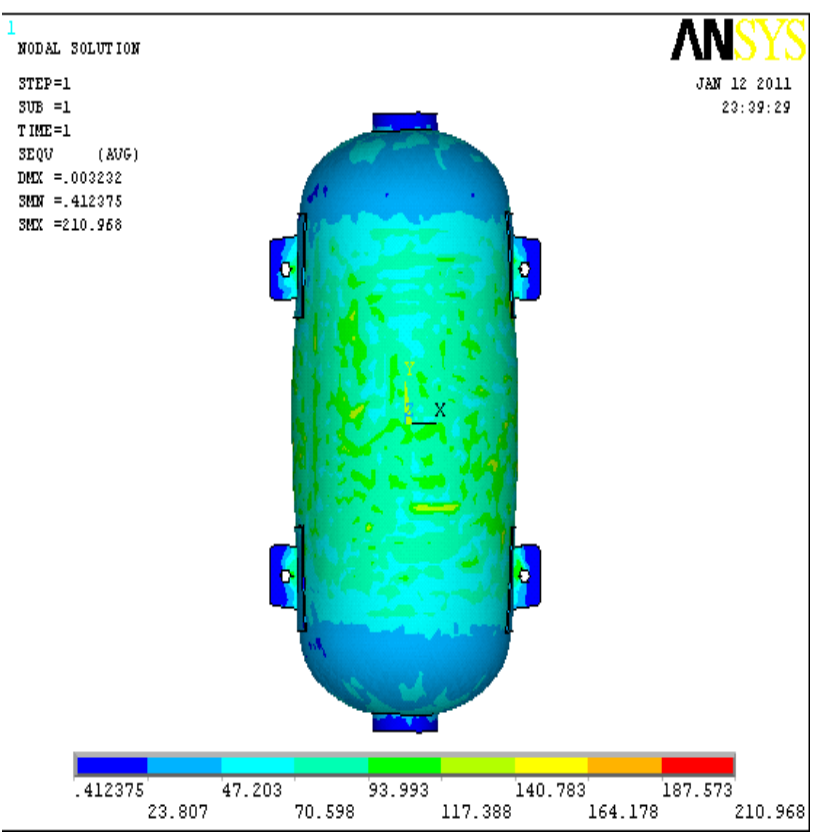

Fig.3.5.(c). $65^{\circ}$ Orientation

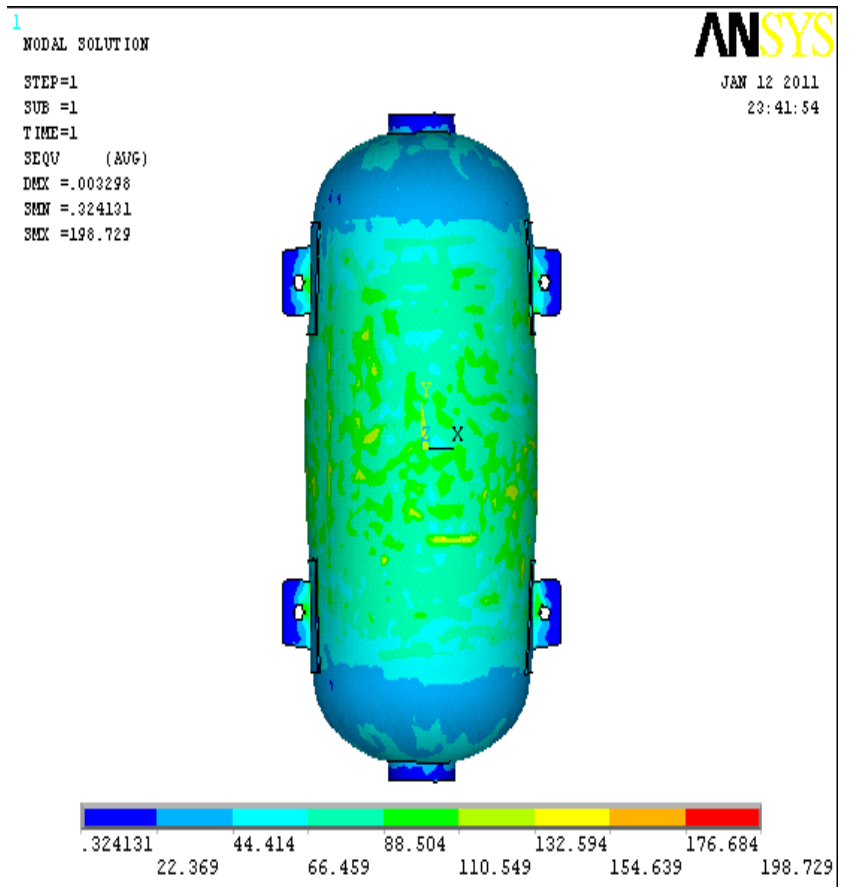

Fig.3.5.(d). $75^{\circ}$ Orientation

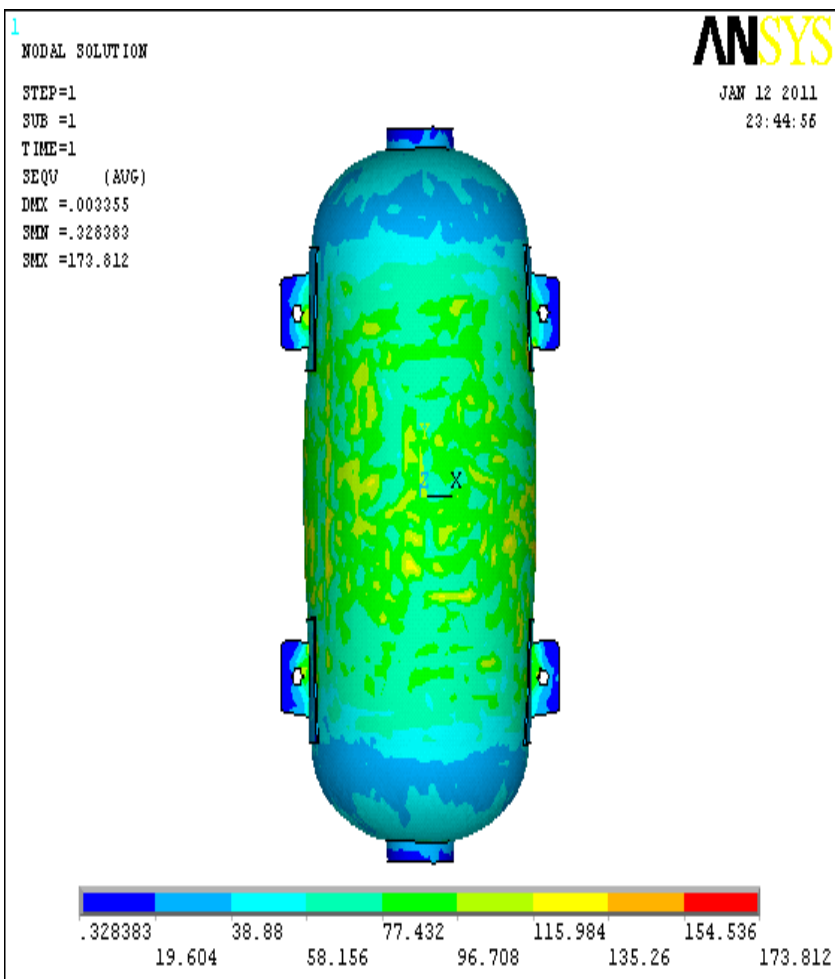

Fig.3.5.(e). $85^{\circ}$ Orientation

Fig.3.5.Vonmisess stresses of Glass Epoxy for 14 layers 


\section{GLASS EPOXY}

Stresses and Deformations at 25 Layers with Different Orientations
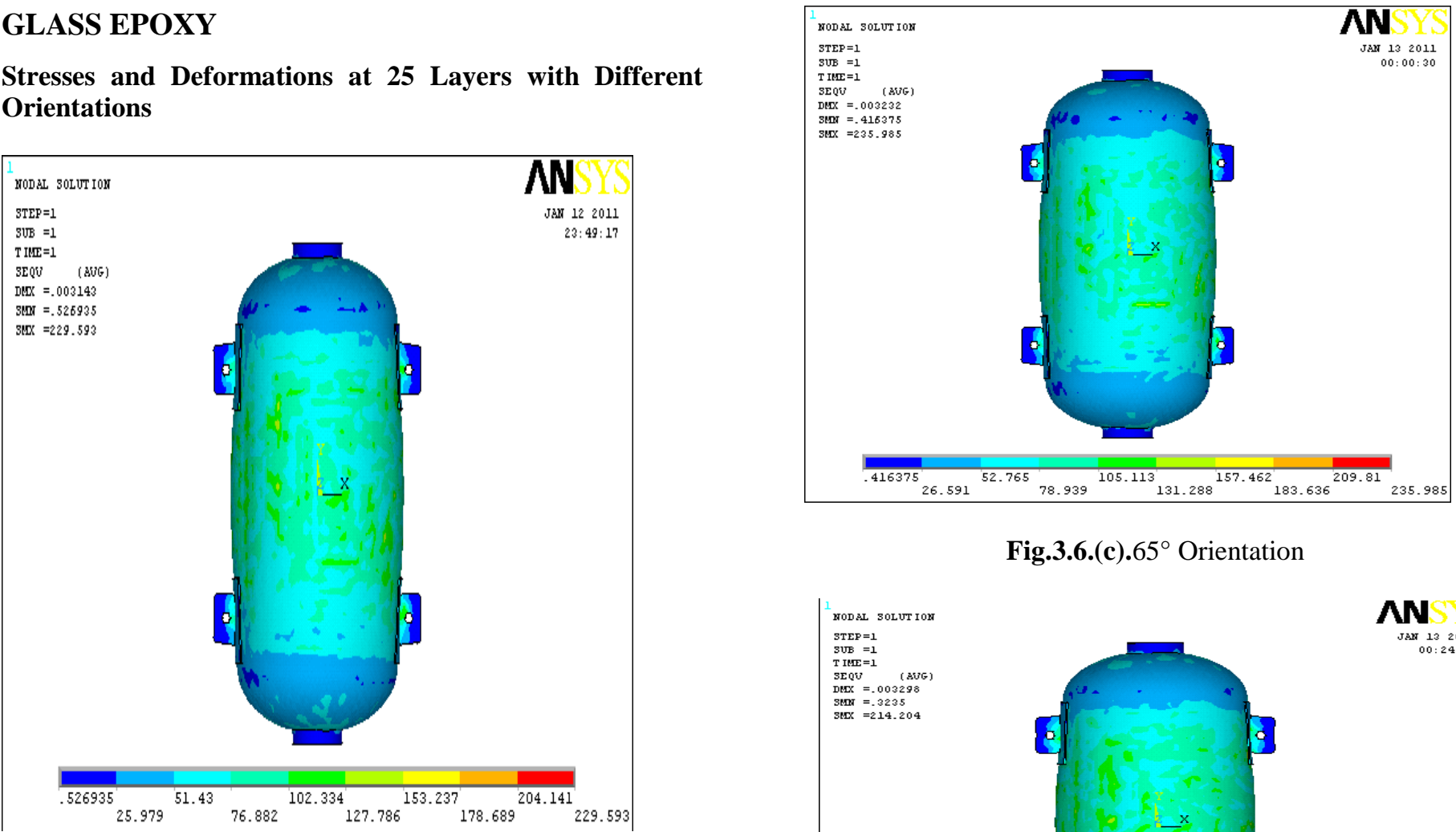

Fig.3.6.(c). $65^{\circ}$ Orientation

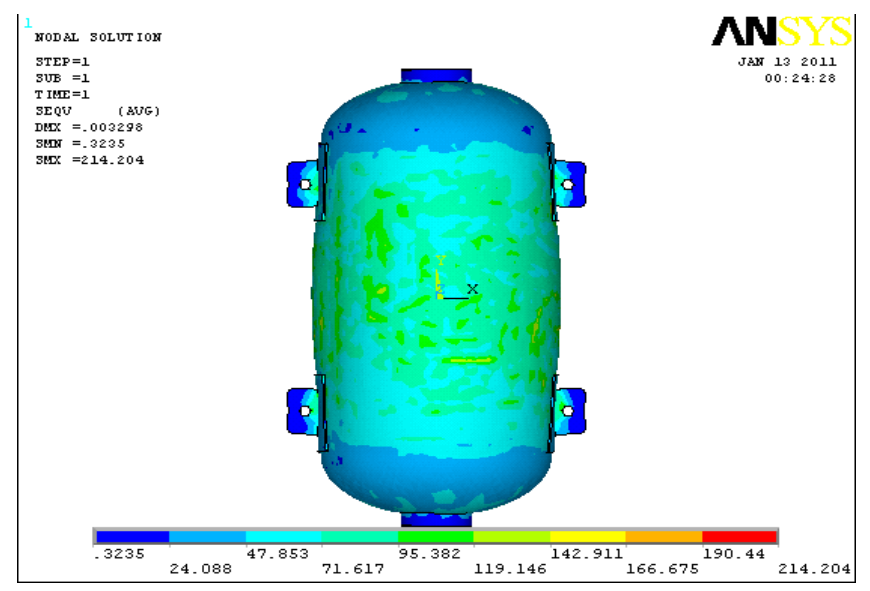

Fig.3.6.(d). $75^{\circ}$ Orientation

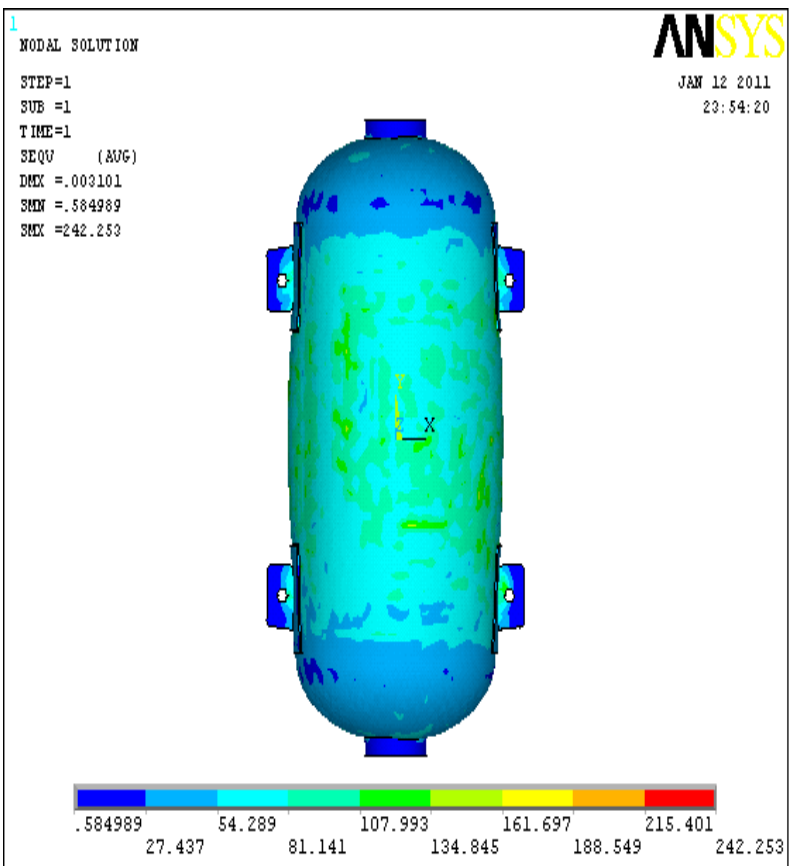

Fig.3.6.(b). $55^{\circ}$ Orientation

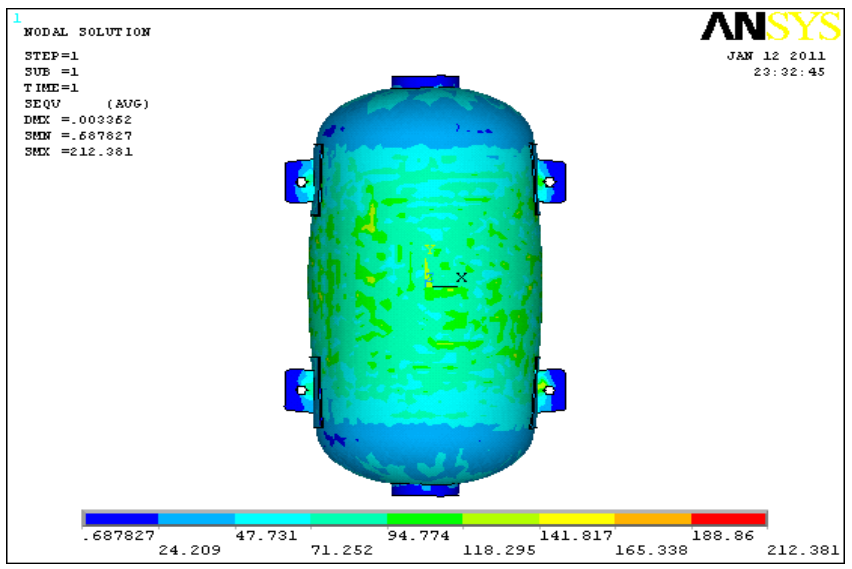

Fig.3.6.(e). $85^{\circ}$ Orientation

Fig.3.6. Vonmisess stresses of Glass Epoxy for 25 layers 


\section{CARBON EPOXY}

Stresses and Deformations at 25 Layers with Different Orientations

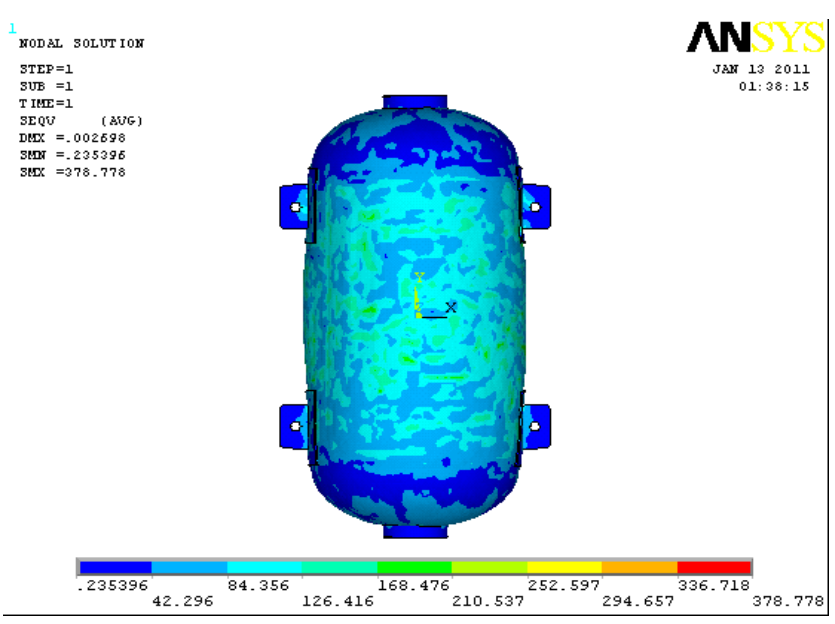

Fig.3.7.(a). $45^{\circ}$ Orientation

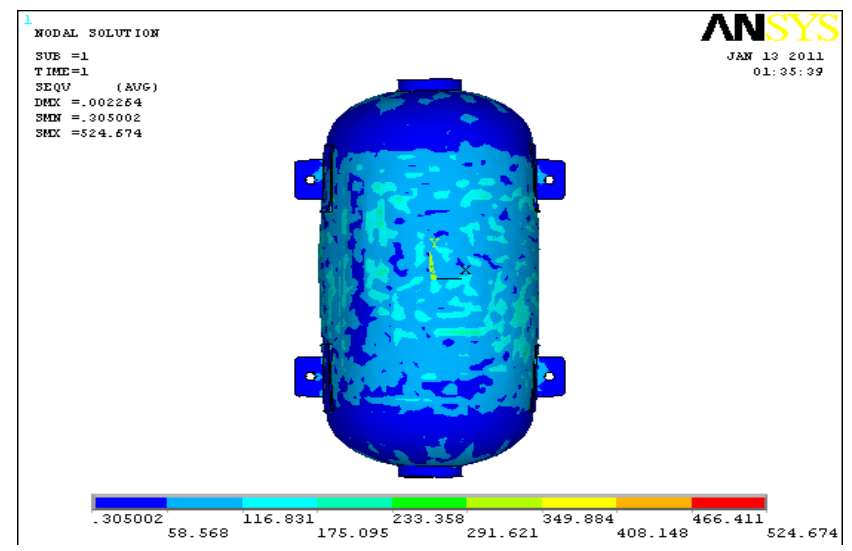

Fig.3.7.(b). $55^{\circ}$ Orientation

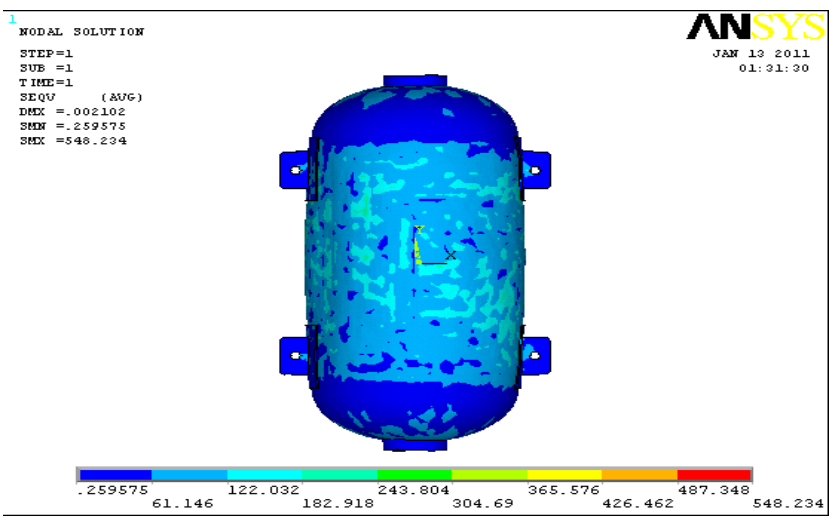

Fig.3.7.(c). $65^{\circ}$ Orientation

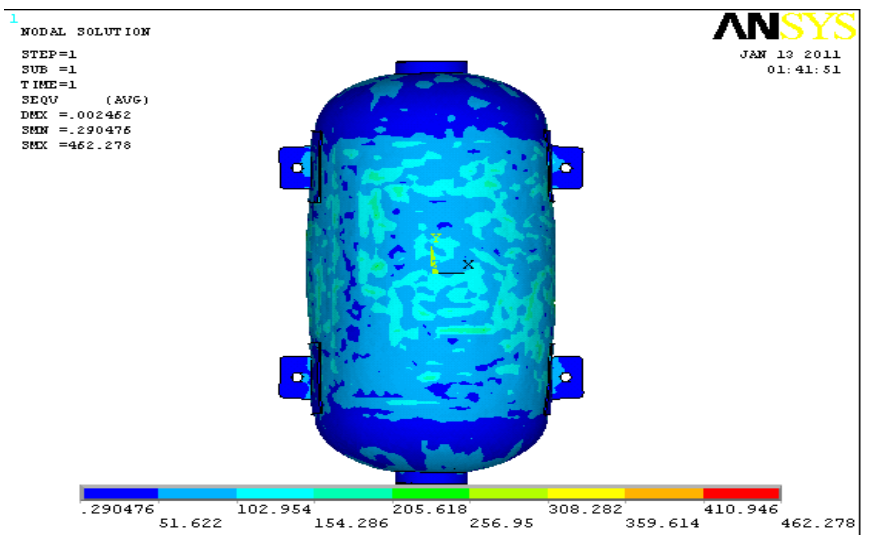

Fig.3.7.(d). $75^{\circ}$ Orientation

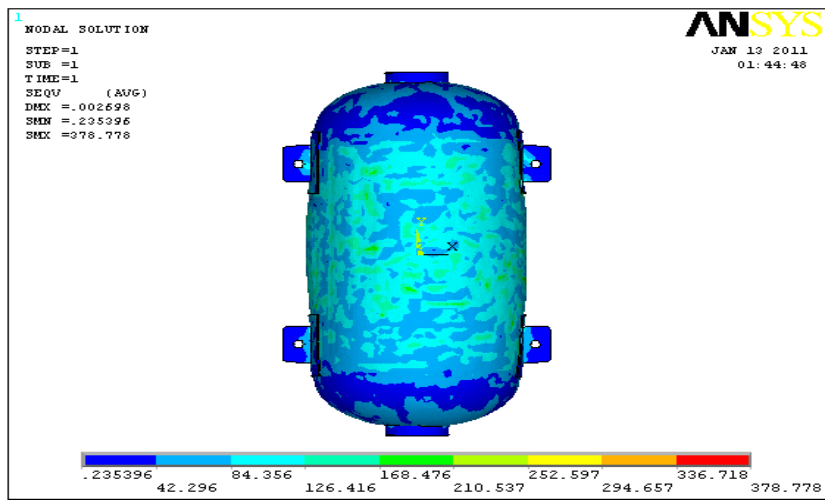

Fig.3.7.(e). $85^{\circ}$ Orientation

Fig.3.7.Von-mises stresses of Carbon Epoxy for 25 layers

\section{BUCKLING FOR CARBON EPOXY WITH STIFFENERS}

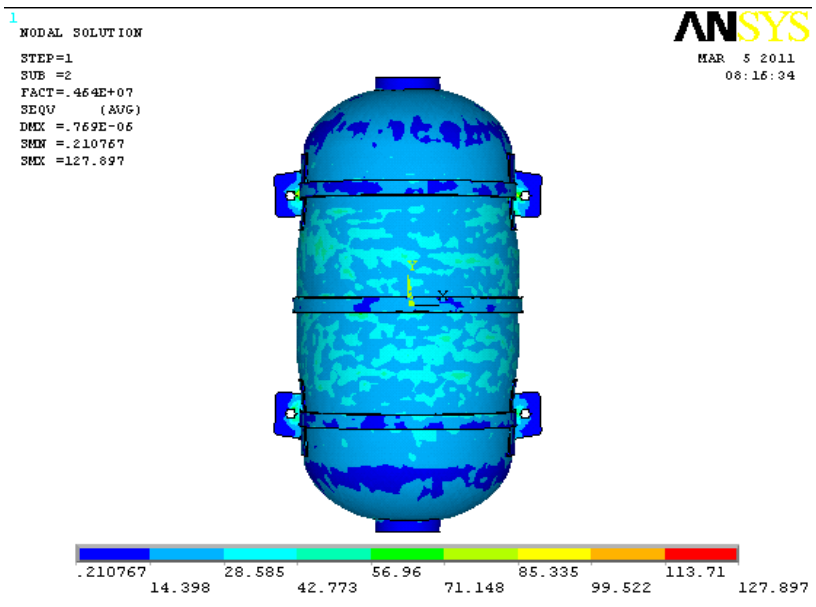

Fig.3.8(a).Stresses 


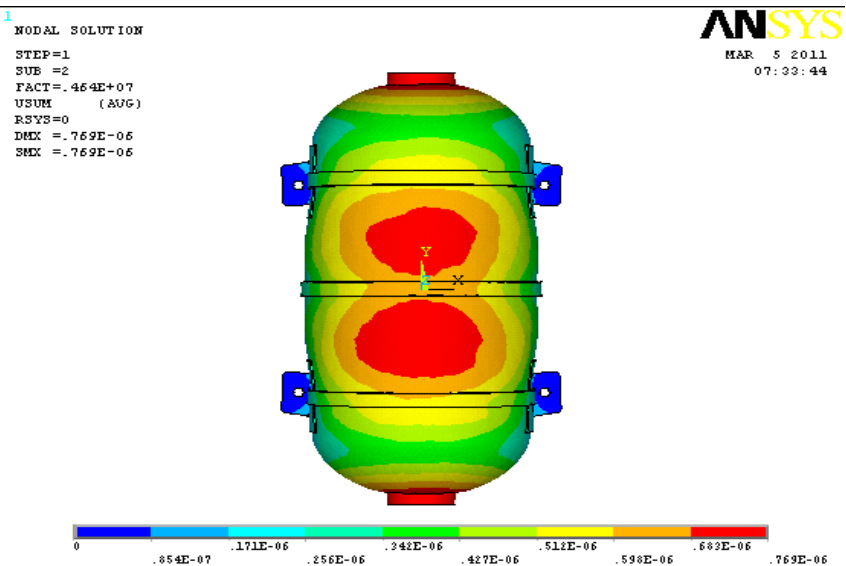

Fig.3.8(b).Deformations

Fig.3.8.STRESSES AND DEFORMATIONS

\section{RESULTS AND DISCUSSION}

In this chapter comparison of vonmisess stresses and deformations of composite materials at optimum angles and optimum layers is presented. Analytical results are compared for prediction of critical pressures with and without stiffeners are investigated. Comparison of two different approaches used to calculate the minimum buckling load is presented. The comparison is based on analysis performed using ANSYS 12.0, the results of finite element analysis and theoretical results are compared.

\section{STRESSES AND DEFORMATIONS OF GLASS EPOXY}

Table.4.1. Stresses and Deformations at Different Layers with Different Orientations

14 layers

\begin{tabular}{|c|c|c|c|c|c|}
\hline Orientation $\left(\theta^{\circ}\right)$ & $45^{\circ}$ & $55^{\circ}$ & $65^{\circ}$ & $75^{\circ}$ & $85^{\circ}$ \\
\hline Deformation $(\mathrm{mm})$ & 0.003181 & 0.003143 & 0.003232 & 0.003298 & 0.003355 \\
\hline Stresses $\left(\mathrm{N} / \mathrm{mm}^{2}\right)$ & 212.381 & 219.367 & 210.968 & 198.729 & 173.812 \\
\hline
\end{tabular}

19 Layers

\begin{tabular}{|c|c|c|c|c|c|}
\hline Orientation $\left(\theta^{\circ}\right)$ & $45^{\circ}$ & $55^{\circ}$ & $65^{\circ}$ & $75^{\circ}$ & $85^{\circ}$ \\
\hline Deformation $(\mathrm{mm})$ & 0.003157 & 0.003127 & 0.003229 & 0.003284 & 0.003358 \\
\hline Stresses $\left(\mathrm{N} / \mathrm{mm}^{2}\right)$ & 216.674 & 231.278 & 227.879 & 205.736 & 196.598 \\
\hline
\end{tabular}

25 Lavers

\begin{tabular}{|c|c|c|c|c|c|}
\hline Orientation $\left(\theta^{\circ}\right)$ & $45^{\circ}$ & $55^{\circ}$ & $65^{\circ}$ & $75^{\circ}$ & $85^{\circ}$ \\
\hline Deformation $(\mathrm{mm})$ & 0.003143 & 0.003101 & 0.003224 & 0.003278 & 0.003362 \\
\hline Stresses $\left(\mathrm{N} / \mathrm{mm}^{2}\right)$ & 229.593 & 242.253 & 235.985 & 214.204 & 212.001 \\
\hline
\end{tabular}

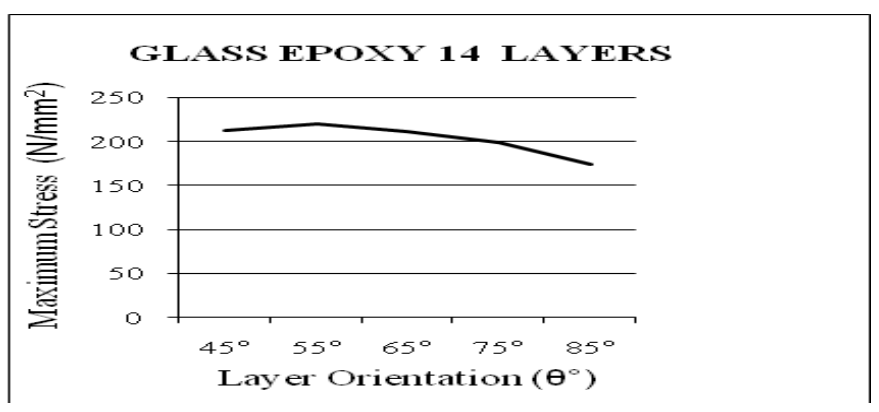

Fig.4.1.(a).Stresses of Glass Epoxy

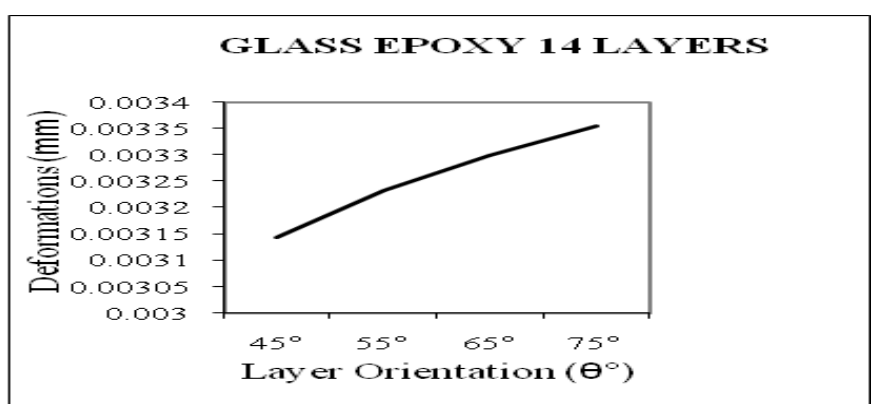

Fig.4.1.(b).Deformations of Glass Epoxy

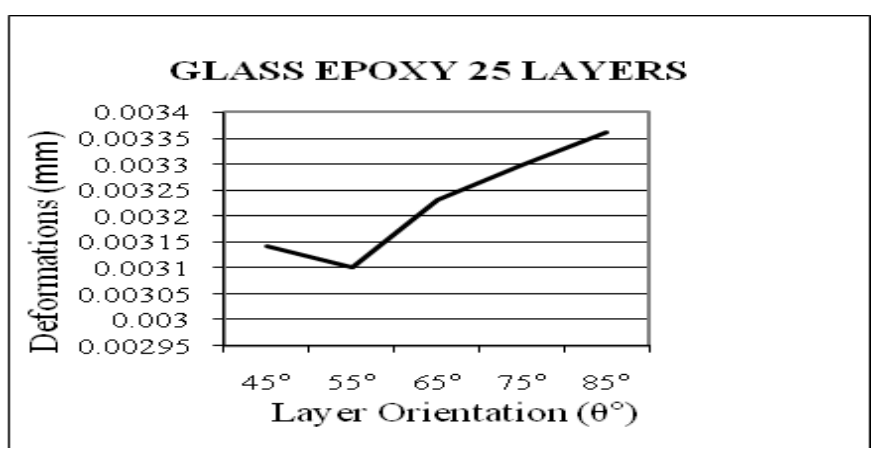

Fig.4.1.(c).Stresses of Glass Epoxy

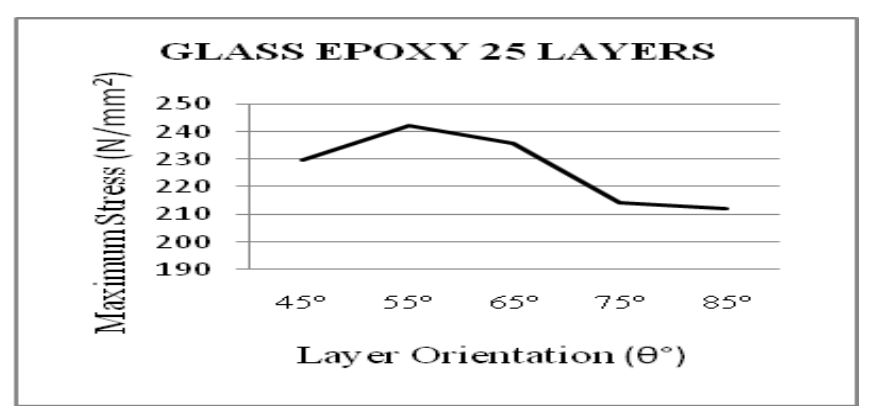

Fig.4.1.(d).Deformations of Glass Epoxy

Fig 4.1 Optimum Angle of glass epoxy. 


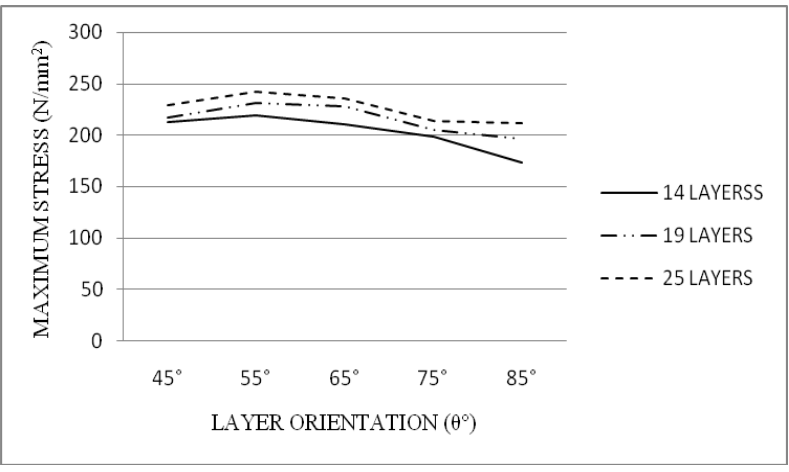

Fig.4.2.(a)Maximum Stresses Plot

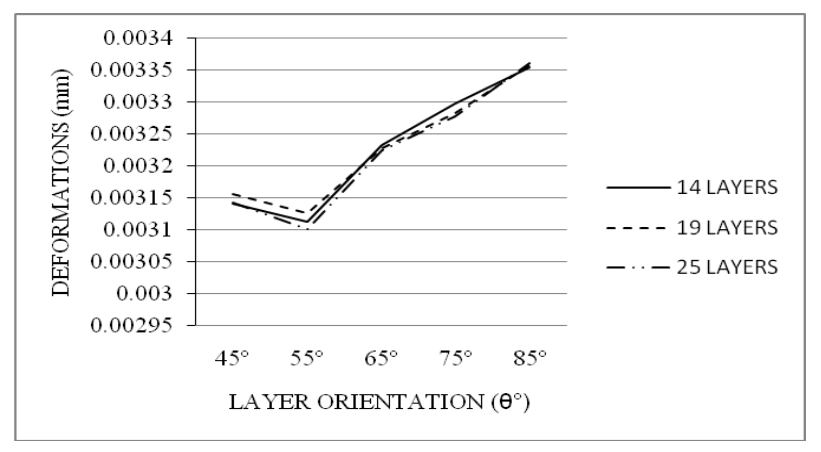

Fig.4.2.(b)Minimum Deformations Plot

Fig.4.2.Stresses and Deformations of Glass Epoxy at Different Number of Layers

\section{STRESSES AND DEFORMATIONS OF CARBON EPOXY}

Table.4.2. Stresses and Deformations at Different Layers with Different Orientations

14 Layers
\begin{tabular}{|c|c|c|c|c|c|}
\hline Orientation $\left(\theta^{\circ}\right)$ & $45^{\circ}$ & $55^{\circ}$ & $65^{\circ}$ & $75^{\circ}$ & $85^{\circ}$ \\
\hline Deformation $(\mathrm{mm})$ & 0.002102 & 0.002158 & 0.002064 & 0.003298 & 0.002827 \\
\hline Stresses $\left(\mathrm{N} / \mathrm{mm}^{2}\right)$ & 365.950 & 376.879 & 417.388 & 397.978 & 332.800 \\
\hline
\end{tabular}

19 Layers

\begin{tabular}{|c|c|c|c|c|c|}
\hline Orientation $\left(\theta^{\circ}\right)$ & $45^{\circ}$ & $55^{\circ}$ & $65^{\circ}$ & $75^{\circ}$ & $85^{\circ}$ \\
\hline Deformation $(\mathrm{mm})$ & 0.002421 & 0.002160 & 0.002087 & 0.002459 & 0.002716 \\
\hline Stresses $\left(\mathrm{N} / \mathrm{mm}^{2}\right)$ & 371.883 & 447.327 & 485.709 & 436.021 & 356.647 \\
\hline
\end{tabular}

25 Layers

\begin{tabular}{|c|c|c|c|c|c|}
\hline Orientation $\left(\theta^{\circ}\right)$ & $45^{\circ}$ & $55^{\circ}$ & $65^{\circ}$ & $75^{\circ}$ & $85^{\circ}$ \\
\hline Deformation $(\mathrm{mm})$ & 0.002264 & 0.002264 & 0.002102 & 0.002459 & 0.002716 \\
\hline Stresses $\left(\mathrm{N} / \mathrm{mm}^{2}\right)$ & 378.778 & 525.674 & 548.234 & 462.278 & 378.778 \\
\hline
\end{tabular}

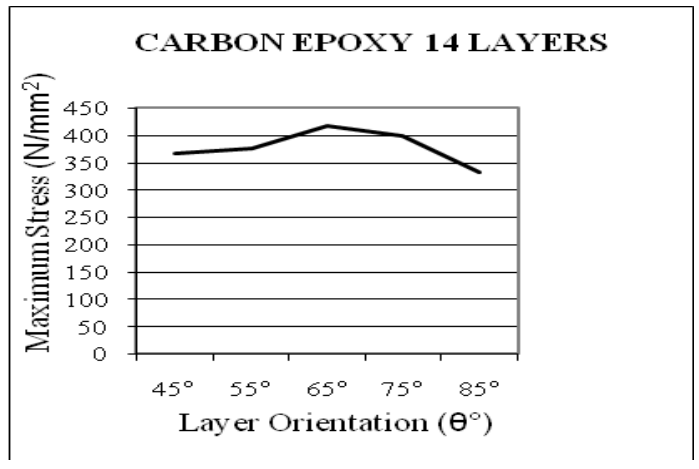

Fig.4.3.(a).Stresses of Carbon Epoxy

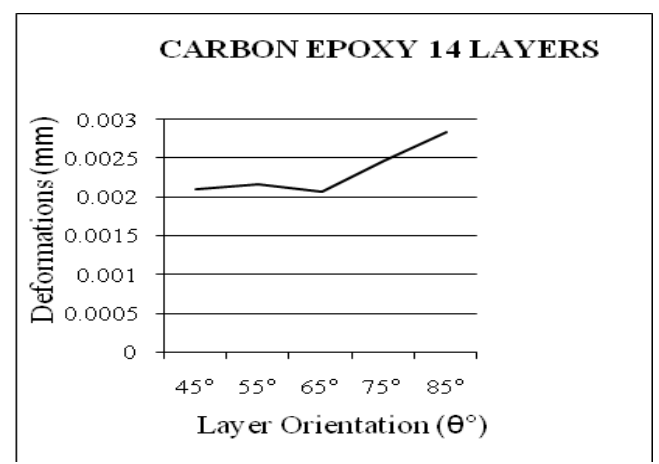

Fig.4.3.(b).Deformations of Carbon Epoxy

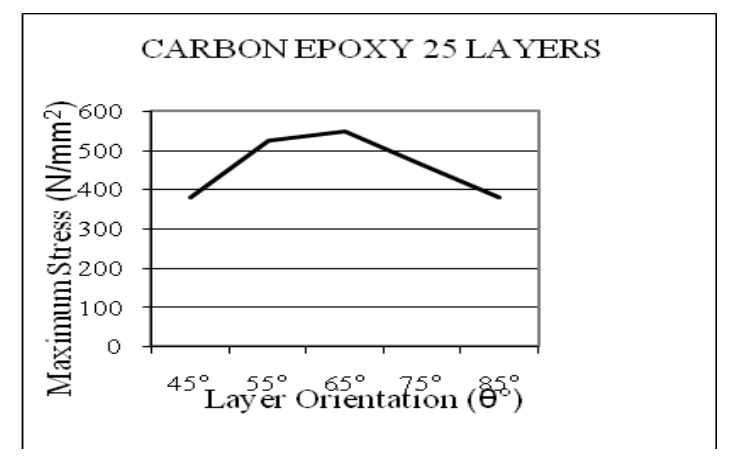

Fig.4.3.(c). Stresses of Carbon Epoxy

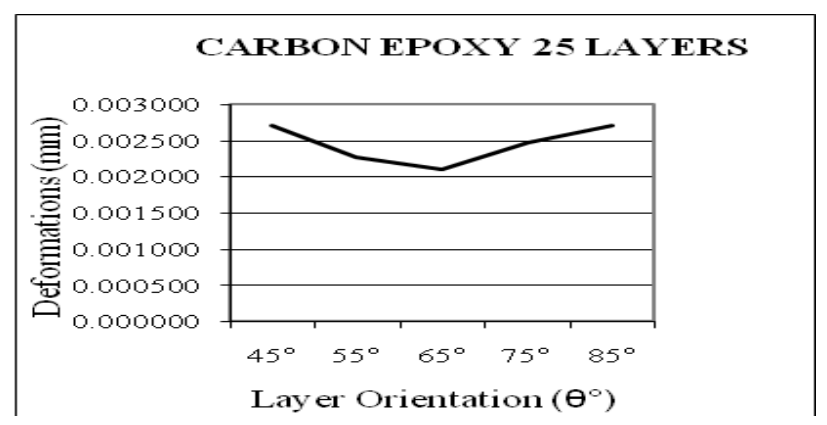

Fig.4.3.(d).Deformations of Carbon Epoxy

Fig 4.3 Optimum Angle of Carbon-epoxy 


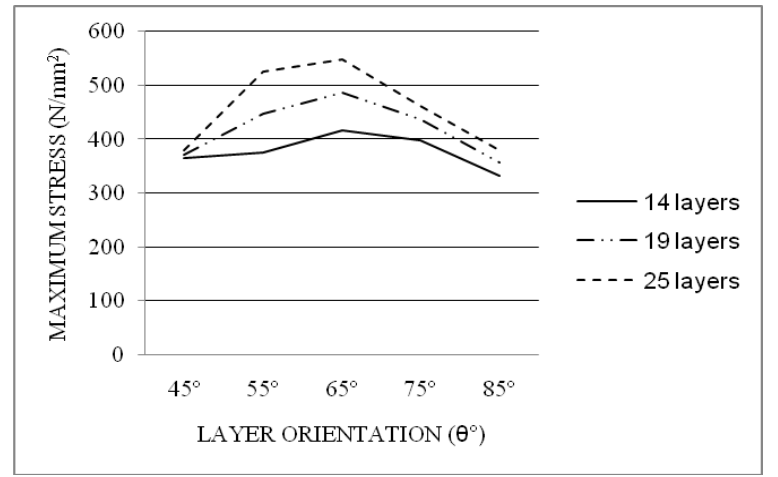

Fig.4.4.(a).Maximum Stress Plot

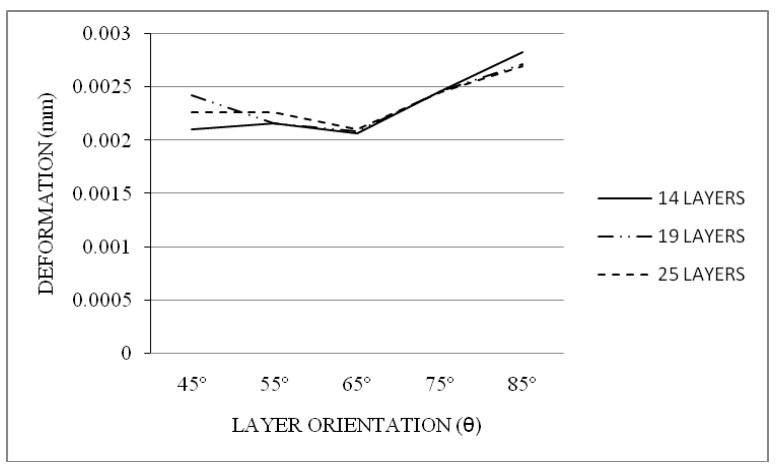

Fig.4.4.(b)Minimum Deformations Plot

Fig 4.4. Stresses and Deformations of Carbon Epoxy at Different Number of Layers

Table.4.4.Critical Pressures of Glass Epoxy

\begin{tabular}{|c|c|c|c|c|c|c|}
\hline \multirow[b]{2}{*}{ sno } & \multirow{2}{*}{$\begin{array}{l}\text { Layer } \\
\text { Thickness } \\
\text { in mm }\end{array}$} & \multirow{2}{*}{$\begin{array}{c}\text { Winding } \\
\text { Angle } \\
\left(\theta^{\circ}\right)\end{array}$} & \multirow{2}{*}{$\begin{array}{c}\text { Maximum } \\
\text { Stresses } \\
\mathrm{N} / \mathrm{mm}^{2}\end{array}$} & \multicolumn{3}{|c|}{ Critical Pressure in Mpa } \\
\hline & & & & $\begin{array}{l}\text { Without } \\
\text { Stiffeners }\end{array}$ & $\begin{array}{c}\text { With } 3 \\
\text { stiffeners }\end{array}$ & $\begin{array}{l}\text { With } 4 \\
\text { stiffeners }\end{array}$ \\
\hline 1 & 0.7 & $45^{\circ}$ & 212.381 & 1.1160 & 3.5908 & 5.033 \\
\hline 2 & 0.7 & $55^{\circ}$ & 219.367 & 1.9561 & 4.0189 & 6.8825 \\
\hline 3 & 0.7 & $65^{\circ}$ & 210.968 & 0.7875 & 2.4760 & 4.7291 \\
\hline 4 & 0.7 & $75^{\circ}$ & 198.729 & 0.6818 & 1.9909 & 4.4659 \\
\hline 5 & 0.7 & $85^{\circ}$ & 173.812 & 0.6273 & 1.8603 & 4.1377 \\
\hline
\end{tabular}

Table.4.5.Critical Pressures of Carbon Epoxy

\begin{tabular}{|c|c|c|c|c|c|c|}
\hline \multirow{2}{*}{ S.ng } & \multirow{2}{*}{$\begin{array}{c}\text { Layer } \\
\text { Thickness } \\
\text { in mm }\end{array}$} & \multirow{2}{*}{$\begin{array}{c}\text { Winding } \\
\text { Angle } \\
\left(\theta^{\circ}\right)\end{array}$} & $\begin{array}{c}\text { Maximum } \\
\text { Stresses } \\
\text { N/mm }\end{array}$ & \multicolumn{3}{|c|}{ Critical Pressure in Mpa } \\
\cline { 5 - 7 } & & $\begin{array}{c}\text { Without } \\
\text { Stiffeners }\end{array}$ & $\begin{array}{c}\text { With 3 } \\
\text { stiffeners }\end{array}$ & $\begin{array}{c}\text { With 4 } \\
\text { stiffeners }\end{array}$ \\
\hline 1 & 0.7 & $45^{\circ}$ & 365.950 & 0.9842 & 3.872 & 6.143 \\
\hline 2 & 0.7 & $55^{\circ}$ & 376.879 & 1.9189 & 3.929 & 6.2718 \\
\hline 3 & 0.7 & $65^{\circ}$ & 417.388 & $\mathbf{3 . 1 4 0 5}$ & $\mathbf{4 . 4 5 1}$ & 7.2903 \\
\hline 4 & 0.7 & $75^{\circ}$ & 397.978 & 1.8620 & 4.208 & 6.8067 \\
\hline 5 & 0.7 & $85^{\circ}$ & 378.778 & 0.6957 & 3.885 & 6.3192 \\
\hline
\end{tabular}

Table.4.6.Critical Pressures of Aramid Epoxy

\begin{tabular}{|c|c|c|c|c|c|c|}
\hline \multirow[b]{2}{*}{ Sne } & \multirow{2}{*}{$\begin{array}{l}\text { Layer } \\
\text { Thickness } \\
\text { in } \mathrm{mm}\end{array}$} & \multirow{2}{*}{$\begin{array}{l}\text { Winding } \\
\text { Angle } \\
\left(\theta^{\circ}\right)\end{array}$} & \multirow{2}{*}{$\begin{array}{c}\text { Maximum } \\
\text { Stresses } \\
\mathrm{N} / \mathrm{mm}^{2}\end{array}$} & \multicolumn{3}{|c|}{ Critical Pressure in Mpa } \\
\hline & & & & $\begin{array}{l}\text { Without } \\
\text { Stiffeners }\end{array}$ & $\begin{array}{c}\text { With } 3 \\
\text { stiffeners }\end{array}$ & $\begin{array}{c}\text { With } 4 \\
\text { stiffeners }\end{array}$ \\
\hline 1 & 0.7 & $45^{\circ}$ & 285.831 & 0.8536 & 1.5756 & 2.1623 \\
\hline 2 & 0.7 & $55^{\circ}$ & 295.146 & 0.9720 & 2.2868 & 2.5791 \\
\hline 3 & 0.7 & $65^{\circ}$ & 320.769 & 2.1259 & 3.9720 & 4.2803 \\
\hline 4 & 0.7 & $75^{\circ}$ & 301.241 & 0.7358 & 2.5473 & 2.7914 \\
\hline 5 & 0.7 & $85^{\circ}$ & 248.023 & 0.5419 & 0.8010 & 1.3342 \\
\hline
\end{tabular}

RESULTS OF BUCKLING ANALYSIS

Table.4.7.Buckling Analysis Results

\begin{tabular}{|c|c|c|c|c|}
\hline \multicolumn{2}{|c|}{} & Glass Epoxy & Carbon Epoxy & Aramid Epoxy \\
\hline \multirow{3}{*}{$\begin{array}{c}\text { Without } \\
\text { Stiffeners }\end{array}$} & Buckling Factor & $2.42 \mathrm{E}+06$ & $3.52 \mathrm{E}+06$ & $2.60 \mathrm{E}+06$ \\
\cline { 2 - 5 } & Max Stresses & 308.012 & 325.918 & 258.643 \\
\cline { 2 - 5 } & Deformations & $2.16 \mathrm{E}-05$ & $6.68 \mathrm{E}-06$ & $6.46 \mathrm{E}-07$ \\
\hline \multirow{3}{*}{ With Stiffeners } & Buckling Factor & $4.07 \mathrm{E}+06$ & $4.54 \mathrm{E}+06$ & $4.30 \mathrm{E}+06$ \\
\cline { 2 - 5 } & Max Stresses & $1.49 \mathrm{E}+02$ & $1.28 \mathrm{E}+02$ & $1.49 \mathrm{E}+02$ \\
\cline { 2 - 5 } & Deformations & $1.13 \mathrm{E}-05$ & $7.69 \mathrm{E}-07$ & $1.13 \mathrm{E}-05$ \\
\hline
\end{tabular}

Comparison of Analytical and Theoretical Buckling Factors for with and without stiffeners

factor of safety is $3 \mathrm{Mpa}\left(P_{c r} / n>1\right.$ safe zone)buckling factor is greater than unity, So Cylinder is safe

Table.4.8.Buckling Factors

\begin{tabular}{|c|c|c|c|}
\hline \multirow{2}{*}{} & Without Stiffeners & With Stiffeners \\
\hline \multirow{2}{*}{ Glass Epoxy } & FEM & 2.2870 & 3.8479 \\
\cline { 2 - 4 } & Theoretical & 1.9561 & 4.0189 \\
\hline \multirow{2}{*}{ Carbon Epoxy } & FEM & 3.3270 & 4.2923 \\
\cline { 2 - 4 } & Theoretical & 3.1405 & 4.4511 \\
\hline \multirow{2}{*}{ Aramid Epoxy } & FEM & 2.3636 & 4.0650 \\
\cline { 2 - 4 } & Theoretical & 2.1259 & 3.9720 \\
\hline
\end{tabular}

\section{CONCLUSION}

[1].The Lamina stacking sequence is appropriate which is free from extension - bending, coupling which reduces the effective stiffness of the lamina, since the laminates are symmetric.

[2].Appropriate number of plies needed in each orientation and thickness of the shell is safe from static and buckling analysis is concerned. The comparison plots obtain desired results for stresses and deformations with lamina orientations for the chosen composite materials. 
[3]. The chosen fiber volume fraction $\mathrm{V}_{\mathrm{f}}=0.65$ and $\mathrm{Vm}=$ 0.35 is acceptable to the present FRP shell working at 3 Mpa internal (Air) pressure.

[4].The fiber orientation $\pm 55^{\circ}$ for glass epoxy and $\pm 65^{\circ}$ angle for carbon and aramid epoxy is correct which optimum value is. From the finite element analysis report the maximum stress obtained in each lamina (for $\pm 55, \pm 65$ degrees winding angle) is less than the allowable working Strength of the FRP lamina. So shell design is safe.

[5].Numerical calculations, Tables and plots obtained for critical pressures supports the comparisons of buckling pressures.

[6].The factor of Safety 3 taken is sufficient for the fiber reinforced Composite material to overcome material design and manufacturing defects. The average critical buckling pressure was obtained from finite element analysis report is $4.0684 \mathrm{~N} / \mathrm{mm}^{2}$ which is more than the maximum working pressure $3 \mathrm{~N} / \mathrm{mm} 2$. Hence the buckling load factor is greater than the unity. Hence the design is safe.

[7].Comparison of stiffened and unstiffened composite shell by both theoretically and analytically, that Analyses supports the stiffened cylinder has more buckling resistance than that of the unstiffened one.

[8]. Increase in shell thickness is shown to increase the buckling resistance of the composite shell. The objective of the analysis and theoretical report shows that fiber reinforced composite shell can minimize the weight of the structure.

\section{REFERENCES}

[1] Alexis A. Krikanov., "Composite pressure vessels with higher stiffeness" 1999 Elsevier science Ltd. Composite structures, vol-48, pp 119-127 (2000).

[2] S.Adali, E.B. Summers \& V.E. Verijenko., "Optimization of Laminated Cylindrical pressure vessels under strength criterion", Composite structures, vol-25, pp 305-312 (1993), University of national Durban 4001, South Africa.

[3] Tae-Uk Kim.,Hvo-Chol Sin., "Optimal design of composite laminated plates with the discreteness in ply angles and uncertain in material properties considered", Computers and Structures 79, pp 2501-2509, (2001).

[4] Levend Parnas., Nuran Katirei.,"Design of FiberReinforced Composite pressure vessels under various loading conditions", Composite structures 58, pp 83-95 (2002).

[5] Graham J., "preliminary Analysis Techniques for Ring and Stringer Stiffened Cylindrical Shells," NASA report TM-108399, March 1993.

[6] Phillips J.L., Gurdal Z.,"Structural Analysis and Optimum Design of Geodesically Stiffened Composite Panels," NASA Report CCMS-90-05, July 1990.

\section{BIOGRAPHIES:}

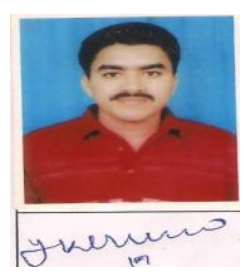

RAO YARRAPRAGADA K.S.S, Associate Professor, Hod, Department Of Mechanical Engineering, B.V.C College Of Engineering, Rajahmundry,

Email:Subbaroayarrapragada@Gmail.Co $m$ Ph.No:7396659639

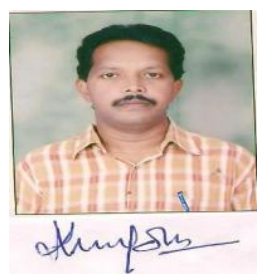

R.KRISHNA MOHAN, Associate Professor, Department Of Mechanical Engineering, B.V.C College Of Engineering, Rajahmundry, Email:Smilesmile.Mohan@Gmail.Com Ph.No:9704338987

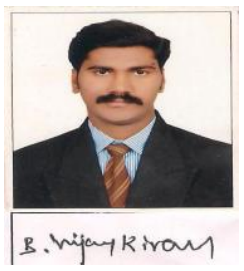

B.VIJAY KIRAN, Assistant Professor, Department Of Mechanical Engineering, B.V.C College Of Engineering, Rajahmundry, Email:B.Vijaykiran@Gmail.Com, Ph.No:8125887525 